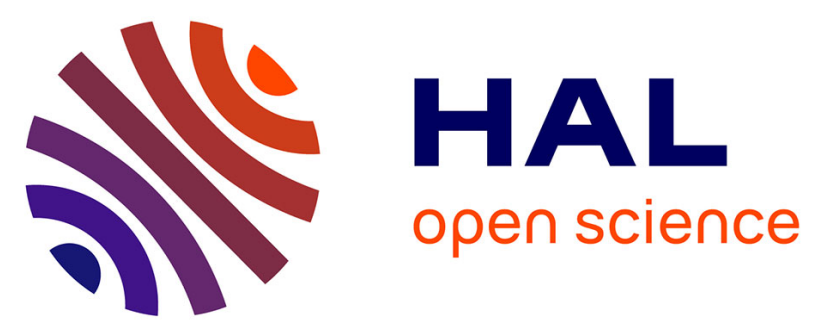

\title{
Large asymmetric polar scarps on Planum Australe, Mars: Characterization and evolution
}

Cyril Grima, F. Costard, Wlodek Kofman, Bertrand Saint-Bézar, Anthony Servain, Frédérique Rémy, Jérémie Mouginot, Alain Herique, Roberto Seu

\section{- To cite this version:}

Cyril Grima, F. Costard, Wlodek Kofman, Bertrand Saint-Bézar, Anthony Servain, et al.. Large asymmetric polar scarps on Planum Australe, Mars: Characterization and evolution. Icarus, 2011, 212 (1), pp.96. 10.1016/j.icarus.2010.12.017 . hal-00725404

\section{HAL Id: hal-00725404 https://hal.science/hal-00725404}

Submitted on 26 Aug 2012

HAL is a multi-disciplinary open access archive for the deposit and dissemination of scientific research documents, whether they are published or not. The documents may come from teaching and research institutions in France or abroad, or from public or private research centers.
L'archive ouverte pluridisciplinaire HAL, est destinée au dépôt et à la diffusion de documents scientifiques de niveau recherche, publiés ou non, émanant des établissements d'enseignement et de recherche français ou étrangers, des laboratoires publics ou privés. 


\section{Accepted Manuscript}

Large asymmetric polar scarps on Planum Australe, Mars: Characterization and evolution

Cyril Grima, François Costard, Wlodek Kofman, Bertrand Saint-Bézar, Anthony Servain, Frédérique Rémy, Jérémie Mouginot, Alain Herique, Roberto Seu

PII: S0019-1035(10)00485-9

DOI: 10.1016/j.icarus.2010.12.017

Reference: $\quad$ YICAR 9668

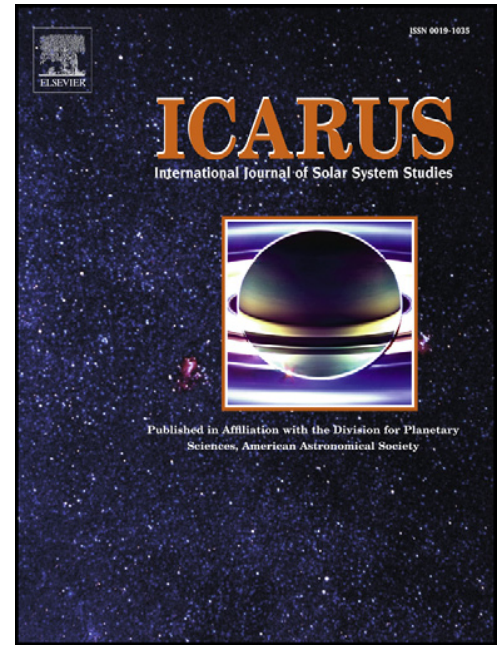

To appear in: $\quad$ Icarus

Received Date: $\quad 12$ April 2010

Revised Date: $\quad 17$ December 2010

Accepted Date: $\quad 18$ December 2010

Please cite this article as: Grima, C., Costard, F., Kofman, W., Saint-Bézar, B., Servain, A., Rémy, F., Mouginot, J., Herique, A., Seu, R., Large asymmetric polar scarps on Planum Australe, Mars: Characterization and evolution, Icarus (2010), doi: 10.1016/j.icarus.2010.12.017

This is a PDF file of an unedited manuscript that has been accepted for publication. As a service to our customers we are providing this early version of the manuscript. The manuscript will undergo copyediting, typesetting, and review of the resulting proof before it is published in its final form. Please note that during the production process errors may be discovered which could affect the content, and all legal disclaimers that apply to the journal pertain. 


\section{Large asymmetric polar scarps on Planum Australe, Mars:}

\section{Characterization and evolution}

Cyril Grima $^{1}$

François Costard ${ }^{2}$

Wlodek Kofman ${ }^{1}$

Bertrand Saint-Bézar ${ }^{2}$

Anthony Servain ${ }^{1}$

Frédérique Rémy ${ }^{3}$

Jérémie Mouginot ${ }^{4}$

Alain Herique ${ }^{1}$

Roberto Seu ${ }^{5}$ (email) cyril.grima@ obs.ujf-grenoble.fr

(email) francois.costard@u-psud.fr

(email) wlodek.kofman@obs.ujf-grenoble.fr

(email) bertrand.saint-bezar@u-psud.fr

(email) berkuts37@hotmail.fr

(email) remy.omp@free.fr

(email) jmougino@uci.edu

(email) alain.herique@obs.ujf-grenoble.fr

(email) roberto.seu@uniroma1.it (tel.) +33476635281

(tel.) +33169154910

(tel.) +33476514147

(tel.) +33169156793

(tel.) +33561332958

(tel.) 2814862146

(tel.) +33476514173

(tel.) +39064458 5943

${ }^{1}$ Laboratoire de Planétologie de Grenoble (CNRS/UJF, UMR5109), 38041 Grenoble Cedex, France

${ }^{2}$ Interactions et Dynamique des Environnements de Surface, (CNRS/UPS, UMR8148), Orsay, France

${ }^{3}$ Laboratoire Etudes en Géophysique et Océanographie Spatiale (CNES/CNRS/UPS), Toulouse, France

${ }^{4}$ University of California, Department of Earth System Science, Irvine, CA 92697-3100 USA

${ }^{5}$ Dipartimento InfoCom, Università di Roma "La Sapienza", Rome, Italy 


$$
\text { Pages }=33 \quad \text { Figures }=12 \quad \text { Tables }=1
$$

1 Running Head: Large asymmetric polar scarps on Planum Australe

4 Corresponding author:

5 Cyril Grima

6 Laboratoire de Planétologie de Grenoble - BP 53

$7 \quad 38041$ Grenoble Cedex 9 - France

8 (tel.) +33476635281

9 (fax.) +33476514146

10 cyril.grima@obs.ujf-grenoble.fr 


\section{Abstract}

27 Numerous scarps with similar characteristics have been observed in the polar layered deposits of

28 Planum Australe, Mars. They are referred to as LAPSs (for Large Asymmetric Polar Scarps)

29 because of their typical cross-section featuring a trough between a straight slope on one side with

30 outcrops of layered deposits and a convex slope on the other side without any outcrops. These

31 LAPSs are restricted to the outlying region of Ultimi Lobe. Topographic data, optical images, and

32 subsurface radar observations have been analyzed and compared to produce a complete

33 morphologic and stratigraphic description of these scarps. In all, 167 LAPS-like features have

34 been identified. All have similar dimensions and characteristics and appear to be deep

35 depressions in the ice. The polar deposits have an average thickness of $1 \mathrm{~km}$ in this region and the

36 LAPS depressions commonly reach half of that thickness. Subsurface data indicate that the

37 depressions could reach bedrock at certain locations. Many surface features of the polar deposits

38 of Mars are considered to be consequences of depositional and/or erosion processes. We propose

39 a mechanical failure of the ice for the LAPSs origin, given the striking similarities in shape and

40 size they show with rollover anticlines above listric faults commonly observed as a crustal

41 extension mode on Earth. This tectonic scenario would imply a substantial outward sliding of the

42 polar deposits in the region of Ultimi Lobe and a low basal shear stress. No information is

43 available to determine whether such a system could be active at present. Confirmation of the

44 "mechanical failure" hypothesis of these LAPSs on Mars is of major importance as it could be a

45 macro-expression of fundamental differences between ice-sheet behavior under Martian and

46 Terrestrial conditions. 
48 Keywords: Mars, polar geology; Mars, polar caps; Ices; Radar observations; Tectonics

\section{1. Introduction}

51 The south and north polar plateaus of Mars - respectively Planum Australe and Planum Boreum 52 are the only known examples of extraterrestrial ice-sheets comparable to those of the Earth. Many

53 striking similarities with the Earth's ice-sheets exist. For instance, the volumes of both Planum

54 Australe and Planum Boreum (respectively $\sim 1.6 \times 10^{6} \mathrm{~km}^{3}$ and $\sim 1.1 \times 10^{6} \mathrm{~km}^{3}$ ) are of the same 55 order as that of the Greenland ice sheet $\left(\sim 2.6 \times 10^{6} \mathrm{~km}^{3}\right)$, with similar average thicknesses of 56 about 1000 to $1500 \mathrm{~m}$ (Plaut et al., 2007; Smith et al., 2001; Weidich, 1995). Moreover, water ice

57 is the major ice-sheet component on both Earth and Mars, with an average impurity fraction that 58 is likely less than $10 \%$ for Planum Australe (Plaut et al., 2007) and close to 5\% for Planum 59 Boreum (Grima et al., 2009). When the mass-balance is positive, the growth process of ice sheets 60 on both planets is driven by the deposition of isochronous layers (known on Mars as polar 61 layered deposits, PLD). Their impurity contents vary with the time of deposition (Cutts and 62 Lewis, 1982; Thomas et al., 1992). Furthermore, the ice of the Earth's ice sheets is crystallized in 63 the hexagonal system (ice-Ih). Although cubic ice (Ice-Ic) could form under Martian conditions 64 by vapor deposition on the surface, it would be metastable (Gooding, 1988). Given the annual rise of surface temperature above the Ic/Ih irreversible transition $(\sim 150 \mathrm{~K})$, the Martian ice sheets are likely exclusively composed of stable ice-Ih as on Earth. And finally, the evolution of the ice

67 sheets on a geological time-scale is mainly driven by Milankovitch orbital cycles (obliquity, eccentricity, and precession variations) leading to planetary climate forcing (Hays et al., 1976;

69 Head et al., 2003), as on Earth. 
70 Nevertheless, the polar environment on Mars is different than on Earth. For instance,

71 temperatures in Martian polar regions can be as low as $150 \mathrm{~K}$ in both hemispheres (Lewis et al.,

72 1999), while the average surface pressure is 0.008 bars with seasonal variations of $\pm 20 \%$

73 (Clifford et al., 2000) and gravity is 0.38 times less than on Earth. Furthermore, the base

74 elevations of the two Martian polar plateaus differ by around $6000 \mathrm{~m}$, far more than on Earth. On

75 Mars, the geothermal heat flow that largely determines the basal temperature of a glacier is

76 estimated to be in the range of 15 to $45 \mathrm{~mW} \mathrm{~m}^{-2}$ (e.g. McGovern et al., 2004; Nimmo and

77 Stevenson, 2000; Reese et al., 1998), lower than the value of $\sim 65 \mathrm{~mW} \mathrm{~m}^{-2}$ for the Earth's

78 continents (Pollack et al., 1993). Consequently, the surface mass balance of the Earth's ice sheets

79 is mainly determined by melting of snow and ice, whereas condensation and sublimation are the

80 dominant processes on Mars (Rognon et al., 2007). Orbital parameters vary with a comparable

81 timescale on Mars and Earth, but with greater amplitudes on Mars. Over the past 10 Myr, Martian

82 obliquity has exceeded $45^{\circ}$ and the eccentricity of the orbit has reached maximums twice that of

83 the Earth's (Laskar et al., 2002; Ward, 1992). Taking all these similarities and dissimilarities into

84 account, Mars can be considered as a full-scale laboratory for the study of the behavior of an

85 Earth-like ice-sheet system over extended conditions. Consequently, the peculiarities observed on

86 the Martian polar plateaus can help us improve our understanding of the Earth's ice-sheet system

87 in general and make the first steps toward meaningful comparative planetology in polar science.

88 With this in mind, this paper provides a geomorphologic description of polar scarps frequently

89 observed in the region of Ultimi Lobe (UL), Planum Australe (see Fig. 1). Despite their km-size

90 and typical asymmetric profile that will be described, equivalent formations have never been

91 reported to date on polar glaciers on Earth. Because of their particular shape, we call these

92 formations LAPSs (for Large Asymmetric Polar Scarps). Until now, only a few studies have 
93 reported such LAPSs on Viking images (Howard, 2000; Thomas and Weitz, 1989), attributing

94 them to an eolian origin. Here LAPSs are described by coupling optical images, surface 95 topography, and radar sounding from recent datasets. This multi-instrumental approach makes it 96 possible to establish profiles of the surface and subsurface of the LAPSs. A LAPS inventory was 97 undertaken and 167 corresponding formations were identified across UL, providing 98 geomorphologic elements to identify and discuss different formation processes for LAPSs. Most 99 of the observations appear to be consistent with a mechanical failure of the ice, analogous to a 100 "listric fault/rollover" system. This tectonic process will be discussed along with certain direct 101 implications.

102

\section{2. Regional context}

Planum Australe overlies heavily cratered highlands that are reported to be Noachian and Hesperian in age (Tanaka and Scott, 1987). The middle-Hesperian Dorsa Argentae Formation (DAF) is thought to be the youngest surrounding terrain of Planum Australe. The Planum Australe mound accumulated during the late Amazonian period (Kolb and Tanaka, 2001) and presently has a maximum thickness of $3700 \mathrm{~m}$ (Plaut et al., 2007). Cratering records estimate the 110 plateau's surface to be as old as 10 to 100 My (Herkenhoff and Plaut, 2000; Koutnik et al., 2002).

111 Signatures of the former extent of the ice sheet have been observed in the DAF where esker-like 112 ridges could be the consequence of past basal-melting (Head and Pratt, 2001; Kargel and Strom, 113 1992; Milkovich et al., 2002). Present-day conditions on Mars preclude exceeding the melting 114 temperature of water ice, except in cases of substantial geothermal anomalies (Clifford, 1987), 115 not likely to be detected by any in-flight instrument, or in the case of saline water (Renno et al., 
2009 and references therein). UL is an outlying region of Planum Australe, opposite DAF and

117 extending over equivalent latitudes. It is the only part of Planum Australe below $80^{\circ} \mathrm{S}$, with

118 latitudes as low as $72^{\circ} \mathrm{S}$ (Fig. 1). It covers $400,000 \mathrm{~km}^{2}$ (i.e. one-third of the entire plateau area).

119 Without this region Planum Australe would be almost perfectly symmetric instead of being offset

120 from the pole. UL seems to have been subjected to a slight outward horizontal motion during

121 recent geological times, revealed by two opposing signatures co-existing along its border. The

122 first is a viscous deformation of the ice, suggested by glacial tongue-like mounds flowing

123 outward in a series of craters dotting the edge of UL (Byrne, 2003). Similar behavior was

124 reported by Head (2001) in the nearby region of Promethei Lingula. The other glacial signature

125 involves brittle processes such as slumping, landsliding and faulting that have also been reported

126 all along the northern border of UL (Byrne, 2003; Murray et al., 2001). These fractures were

127 interpreted as evidence of modest basal sliding of the whole region, seen as a brittle plate.

128

$129 *$ Location of Fig. 1 (1.5 column width).

130

131 3. Data

132

133 Five different data sources were used for this study:

134 (i) The digital elevation model of the surface acquired by the Mars Orbiter Laser Altimeter 135 (MOLA) (Smith et al., 2001). We used the gridded polar map at 256 pixels $/{ }^{\circ}(\sim 230 \mathrm{~m} /$ pixel $)$ with 136 a vertical accuracy of $1 \mathrm{~m}$. 
137

138

139

140

141

142

143

144

145

146

147

148

149

150

151

152

153

154

155

156

157

158

159

160

(ii) Visible images from the High Resolution Imaging Science Experiment (HiRISE) with a resolution of 25 to $32 \mathrm{~cm}$ /pixel (McEwen et al., 2007). Only a few HiRISE images are available over UL.

(iii) Visible images from the High-Resolution Stereo Camera (HRSC) experiment with a resolution of 10 to $20 \mathrm{~m} /$ pixel (Jaumann et al., 2007). Despite a more limited resolution than HiRISE, HRSC were retained because of its high coverage of the UL region.

(iv) Radar subsurface cross-sections (radargrams) of Planum Australe from SHAllow RADar (SHARAD) (Seu et al., 2004). The radar signal (20 MHz) penetrates as deep as $~ 1500 \mathrm{~m}$ into water ice materials with $10 \times 300 \mathrm{~m}$ vertical $\times$ along-track resolution. The radar waves are backscattered by dielectric gradients along the propagation path that are closely related to impurity rate variations in the ice. Thus, SHARAD is able to detect the layers forming Planum Australe. In UL, the detection signal is faint and can suddenly disappear before reappearing tens of kilometres downtrack. This could be due to a low dielectric contrast between isochronous layers. However, the regional density of SHARAD data is high and it was possible to select some radargrams to support morphologic interpretations. Initially, radargrams have a vertical timescale representing the time delay of the echoes. They have been migrated in depth by using a relative dielectric constant of 3.10 as inferred by Grima et al. (2009) for the nearly pure ice of Planum Boreum. Off-nadir surface reflections (clutter) can generate highly delayed echoes that can be confused with subsurface structures. Adaptation of radar simulation developed by Nouvel et al. (2004) allowed us to identified the biggest clutters.

(v) Bedrock elevation as mapped by Plaut et al. (2007) based on the Mars Advanced Radar for Subsurface and Ionosphere Sounding (MARSIS) data (Picardi et al., 2005). Compared to SHARAD, the MARSIS wavelength (1.8 to $5 \mathrm{MHz}$ ) provides a lower vertical resolution of $\sim 80$ $m$ in the ice. However the signal penetrates deep enough into Planum Australe to be clearly back- 
161

162

163

164

165

166

167

168

169

170

171

172

173

174

175

176

177

178

179

180

181

182

183

scattered by the bedrock. The vertical uncertainty on the inferred basal topography is assumed to be $200 \mathrm{~m}$ (Plaut et al., 2007). It must be emphasized that this bedrock elevation map were obtained by interpolation of a limited-density dataset: the resolution was sufficient to get the basal regional trend but not to detect local anomalies of the bedrock.

\section{Morphological description}

\subsection{Spatial shape and distribution}

The first recognizable feature of the LAPSs is their spatial shape. They appear to be arch-shaped, tens of kilometers long, and are distributed over the surface of the ice (Fig. 1). Howard (2000) described this particular signature as a scalloped or a "gull-winged" shape. This criterion enabled us to identify 167 LAPSs over Ultimi Lobe (Fig. 2). This count is not accurate for two reasons: (i) sometimes up to three or more LAPSs are aligned and/or connected, often making it difficult to precisely define how many LAPS there actually are; (ii) the arch-shaped LAPSs can be confused with the rims of shallow-buried craters. To avoid this, we do not consider scarps that are obviously linked to a circular structure (an example is shown Fig. 5B). However, since the surface topography is quite disturbed, we cannot rule-out that some less obvious crater-linked formations were counted. The count shows that LAPSs are widespread over Ultimi Lobe. Their "horn-to-horn" width is in the range of 10 to $20 \mathrm{~km}$, while some can reach $50 \mathrm{~km}$. Most of them are gathered in aligned series. As already observed by Howard (2000), their regular size and close spacing cannot be universally explained by a crater rim origin. This strongly supports the assumption that most of the LAPSs considered in this study are not mainly linked to shallow- 
184

185

186

187

188

189

190

191

192

193

194

195

196

197

198

199

200

201

202

203

204

205

206

207

buried craters. As shown in Fig. 3, the concave sides of the LAPSs never face the South Pole and the dominant orientation is not towards the equator (i.e. azimuth $=0^{\circ}$ ). Neither is the orientation constant with respect to longitude. For instance, in a given area, adjacent LAPSs can be almost right-angled (e.g. white arrows in Fig. 2). The regional orientation in the polar stereographic view is also a relevant parameter. Let us define $0^{\circ}$ and $90^{\circ}$ as the angles for which LAPS concavities face the bottom and the right border of the map respectively. Figure 3 shows this regional orientation in a circular histogram. The whole set of LAPSs appears to be essentially directed towards the same quadrant between $0^{\circ}$ and $90^{\circ}$.

* Location of Fig. 2 (no particular restriction on the size).

* Location of Fig. 3 (no particular restriction on the size).

\subsection{Cross-section}

The second noteworthy feature is the asymmetric shape of LAPS cross-sections (giving them the second letter of their acronym). They exhibit a trough between a straight slope on one side, comparable to a scarp, facing a gentle convex upward slope on the other side that flattens as it rises. Figure 4 and the cross-sections in Fig. 6 illustrate this profile. The LAPS system forms extremely deep troughs in the ice with respect to the local ice thicknesses. The height of the scarps ranges from $200 \mathrm{~m}$ to $700 \mathrm{~m}$ with an average value of $400 \mathrm{~m}$. The East part of UL (left side on the map) hosts the highest scarps. The resulting troughs regularly penetrate Planum Australe to half its thickness. In some cases, the trough reaches the top value of the basal elevation estimated by MARSIS. This usually occurs when the trough seems flat and parallel to the bedrock slope, as shown in Fig. 6 for cross-sections $1 b-1 b$ 'and $3 b-3 b$ '. This leads to the 
possibility that the bedrock could in some cases become locally exposed. Some LAPSs exhibit a more complex topography on the side of the convex slope (cross-sections $4 a-4 a$ 'and $4 b-4 b$ '). are essentially located in the heart and in the Eastern part of UL (left side of Fig. 2). Despite these very particular topographies - asymmetric and deep troughs - it is important to emphasize the relative flatness of the system. The slope of the scarps ranges from $2^{\circ}$ to $15^{\circ}$, with an average 214 value of $10^{\circ}$. Indeed, the mean horizontal distance between the foot and the top of the straight 215 slope is $3.5 \mathrm{~km}$. Therefore, the horizontal scale of the LAPS system is roughly an order of 216 magnitude larger than the ice thickness. This thinness and flatness are highlighted in Fig. 6 by the 217 inserts that display no vertical exaggeration.

* Location of Fig. 4 (no particular restriction on the size).

\subsection{Hillocks}

Another feature is regularly (but not systematically) superimposed on the typical cross-section described above i.e. a ridge that can be observed along certain scarp crests (indicated by black arrows in Fig. 6), similar to elongated hillocks. We did not find any relation between the heights

226 of the hillocks and the height of the straight slope or any other distinctive dimensions. The hillock / straight-slope height ratio is usually $<0.2$, although around 10 LAPSs, mostly concentrated in 228 the far-east side of UL, have a ratio $>0.5$. However, note that the hillocks remain extremely flat, as they are stretched horizontally over 2 to $5 \mathrm{~km}$. 
* Location of Fig. 6 (as wide as possible).

\section{5. Stratigraphy}

The behavior of the internal structure of any geological formation is necessary to understand its 237 origin. Consequently the structure of the PLD beneath the LAPS and information from subsurface radar are essential. However, as noted in section 3, the layers detected by SHARAD in

239 the UL region correspond to faint signals. To support the radar observations, we compared them with visible images from HiRISE and HRSC. These cross-analyses made it possible to draw a

241 partial pattern for the polar layers.

242 Figure 7 shows two LAPS cross-sections associated with two SHARAD radargrams. HRSC 243 images of the surface along the groundtracks are also shown. The radargram of cross-section 5-5,

244 clearly shows horizontal layers on the straight-slope side (right side of the picture), leading to the 245 hypothesis that the scarp includes outcrops there. On the other side, the layers below the convex 246 slope are curved, parallel to the surface and plunging. Unlike the case on the straight-slope side, 247 no outcrops are expected on the convex slope. On the HRSC image associated with this cross248 section, polar layer outcrops can be distinguished as gathered lines of various albedos 249 perpendicular to the ground-track. The change in albedo is due to slope and dust content variations from one layer to another. The cross-section locates these outcrops in an area 251 corresponding exclusively to the straight slope, confirming the radar observation. Conversely, the 252 HRSC image does not show any such signature on the convex slope, consistent with the previous 253 hypothesis that the layers are curved downward and do not outcrop on this side. Cross-section 6254 6' shows similar behavior, although the bending of the convex-slope layers is not as clear on the 
255 radargram because of the faint detection signals. However the associated HRSC image reveals

256 that outcrops occur only on the straight slope, implying that the convex-slope layers also plunge

257 downward as supposed.

258 This asymmetric behavior of the polar layers (outcrops on the straight slope and downward

259 bending below the convex slope) cannot be verified by radar data for the entire set of LAPSs

260 because of the poor layer detection in the UL region as mentioned above. However, visual

261 inspection of available images shows that outcropping on the straight slope only is a common

262 signature of the LAPSs. Figure 8 is an example of a HiRISE image over two successive LAPSs.

263 The asymmetric outcrop is clear for both; however the cross-section path cuts the end of the

264 second LAPS leading to progressive fading of the outcrops.

265 Finally, it is not possible to comment on the structure just under the LAPS troughs given that no

266 formation is detected by radar. This does not necessarily mean that no reflector is present. It is

267 more likely due to the straight slope, refracting most of the back-wave power offside with respect

268 to the instrument, making underlying features hard to detect. In addition, the recurrent clutter

269 echoes at this location could be strong enough to hide faint signals from the subsurface.

270

$271 *$ Location of Fig. 7 (as wide as possible).

$272 *$ Location of Fig. 8 (as wide as possible).

273

274 6. Interpretations

275 
276

277

278

279

280

281

282

283

284

285

286

287

288

289

290

291

292

293

294

295

296

297

298

299

The results of the morphologic description of the LAPS surface and the stratigraphic study are summarized in Fig. 4. The different indicators support that Fig. 4 is a roughly general model for the LAPS morphology. We will now look at the possible origins of the LAPSs.

\subsection{Crater filling as a possible origin of LAPSS}

The arched shape of the LAPSs naturally suggests a possible link with craters. Some of the circular objects on UL are obviously buried craters that lay either on buried layered deposits (paleo-surface) or on the bedrock. Subsequent accumulation of deposits of ice on these irregularities would lead to an increasingly smooth surface topography that would nevertheless conserve a spatial signature of the initial formations with a decreasing vertical relief. In particular, the common hillocks observed along the crests could be easily interpreted in terms of crater rim prominences. However, the observed LAPSs are just semi-circular with no sign of an opposite and symmetric formation to complete the circle. Nevertheless, it should be possible to fill a particular crater or bedrock formation with successive deposits of layers in order to obtain a LAPS morphology. One possibility would be to start with a crater that has been asymmetrically eroded. Uneven deposition of ice on a crater is another mechanism that could produce a LAPS by accumulation of the deposits preferentially on one side. However, even if a LAPS production process based on crater filling can be imagined, it does not easily explain the spatial repetitions that are observed (Howard, 2000). The repetition and similar dimensions of the LAPSs as well as their local layout in aligned formations does not support craters as the origin given that crater locations and diameters are basically random.

\subsection{Erosion processes as a possible origin of LAPSS}


301 Howard (2000) performed a complete survey of optical images in order to detect surface 302 signatures of eolian processes over the PLDs. He noticed similarities between the arched shape of 303 LAPSs and barchan dunes formed by deposition of wind-transported sand. Since this study, the 304 availability of an accurate digital elevation model (MOLA) allows us to show that LAPSs are instead deep depressions in the ice. This raises the possibility of LAPS formation by erosion of the ice, which could be driven either by eolian processes or sun sublimation.

The long-term efficiency of the wind loaded with abrasive particles to shape the surface of the ice is well known (e.g. Howard, 2000; Koutnik et al., 2005). Wire brush terrains, snakes, and trailing grooves are especially common eolian formations encountered on Planum Australe. They extend for hundreds of kilometers and are associated with a decameter vertical scale (Koutnik et al., 2005). The objects thus formed have a vertical / horizontal ratio several orders of magnitude smaller than the typical dimensions of LAPSs. However, the relatively uniform orientation of the LAPSs is consistent with an eolian origin, except for the quasi-perpendicular LAPSs found in a single region as shown in Fig 2.

At the North Pole, Planum Boreum exhibits numerous spiral troughs in its margin. Their asymmetric cross-sections are quite similar to those of the LAPSs. Although their precise origin is not yet well understood, northern troughs are thought to be sustained by a process involving solar sublimation of the exposed slope together with deposition of water vapor on the pole-facing slope, leading to an asymmetric outcrop (e.g. Pelletier, 2004 and references therein). Ice flow and katabic winds could also play a key role in their evolution (Fisher et al., 2002; Smith et al., 2010). In particular, Smith et al. (2010) suggest trough migration to explain the asymmetric stratigraphy of the troughs. They suggest that katabatic winds remove material from the upwind slopes of a trough and carry it to the downwind slope. However, northern troughs have linear shapes up to 
324 hundreds of kilometers long, roughly arranged in a spiral leading out from the pole all around the 325 cap, while LAPSs are individually restricted to a 20-km arch shape in the heart of a single region 326 of Planum Australe. In addition, the hillocks often observed along the crests of the LAPS are not 327 observed on the northern troughs. Thus, spatial shape and distribution considerations do not 328 contribute to a common origin of the northern and southern scarps. Furthermore, LAPS 329 orientations are not preferentially sunward and a number of them have their straight slope with 330 outcrops almost parallel to longitudes, meaning that sun sublimation is not likely to have initiated 331 them.

\subsection{Tectonic scenario}

On Earth, a common mode of crustal extension consists in the development of listric normal fault and their associated rollover anticline. Because of their crucial importance for commercial prospecting (hydrocarbon traps in faulted/folded strata), these structures have been studied extensively (e.g. Dula, 1991; Poblet and Bulnes, 2005; Shelton, 1984).

339 Listric faults can be defined as curved normal faults in which the fault surface is concave 340 upwards, its dip angle decreasing with depth. These faults occur in extension zones where there is 341 a main detachment fracture following a curved path that connects to a horizontal décollement.

342 The hanging-wall may develop a syn-tectonic rollover anticline classically interpreted as a direct consequence of layer bending during hanging-wall displacement above the listric normal fault

344 (Fig. 9). The rollover geometry is conventionally interpreted as a direct consequence of the 345 gradual bending of the strata of the hanging-wall moving along the listric normal fault. The shift 346 changes with a horizontal component that increases with depth to become parallel to the 
347

348

349

350

351

352

353

354

355

356

$357 *$ Location of Fig. 9 (1 column width).

$358 *$ Location of Fig. 10 (1 column width). high or where materials are weak.

décollement. It is generally accepted that the latter is a level where fluid pressure is abnormally

The morphology of the LAPSs observed on Mars is very similar to the above listric fault formation on Earth. They show a topographic asymmetry with a steeply dipping scarp facing a gentle flexure that flattens with elevation, producing a convex morphology. The radargram cross-section confirms this similarity by revealing the subsurface layer geometry. The similarity with a terrestrial example is striking (see Fig. 10). The footwall compartment clearly shows horizontal layers that appear to intersect with the escarpment, while the hanging-wall shows a flexural geometry with a gradual downward bending of layers toward the scarp.

The LAPS morphology on Mars thus appears to correspond to the formations produced around a listric normal fault on earth. The length of the scarp may correspond to the fault slip. The fault 362 has a strong dip angle with respect to the outcrop, which decreases with depth to reach a level 363 that may be the ice/bedrock interface.

364 Figure 9C shows a more complex evolution of the system with some subsequent faulting and 365 tilting of individual blocks (Davison, 1986; Hauge and Gray, 1996; Song and Cawood, 2001; Williams and Vann, 1987). It is similar to the surface characteristics observed on cross-sections $3674 a-4 a$ ' and 4b-4b'. The presence of this rollover geometry suggests extensive regional tectonic activity related to the slow sliding of Planum Australe on a geological time scale. In some 369 particular situations, the semi-circular topographic scarp may correspond to some pre-existing 370 impact crater rims associated with a circular and normal faulting system. Such structural systems 
371 favor the preferential sliding of the UL polar layered region. The implied horizontal displacement

372 would be substantial (several kilometers, depending on the LAPS length) and mainly directed 373 toward the quadrant of the circular histogram Fig. 3.

374 The rollover hypothesis can be tested by modeling the tectonic process, for instance using the 375 area balance technique conventionally used for the restoration of a balanced cross-section

376 (Davison, 1986; Faure and Seguret, 1988; Gibbs, 1983). The principle is based on the concept of 377 plane strain or volume conservation of cross-sectional area. In Fig. 9B, it consists in measuring 378 the area below the regional datum (area A) which is, in the case of volume conservation, equal to 379 the volume displaced (area B). The latter is the product of the horizontal extension and the depth 380 of the décollement $(\mathrm{A}=\mathrm{B}=\mathrm{h} \times \mathrm{d})$. In such a model, it is assumed that the hanging-wall deforms 381 by simple shear and that the footwall remains undeformed throughout the extension (White et al., 382 1986). The horizontal displacement $\left(\mathrm{H}_{\mathrm{r}}\right.$ in Fig. 11) can be directly inferred from the cross383 sections (if the latter is parallel to the tectonic strike). Indeed, in the case of a listric fault, the 384 deformation of the hanging-wall must be similar to simple shear deformation. Most of the shear 385 angles used for earth materials are around $60^{\circ}$ (Dula, 1991). Compensation to $60^{\circ}$ of potential 386 gap implies that the cutoff point of the hanging-wall is projected at $60^{\circ}$ with respect to the surface 387 of the listric fault (Fig. 11). The horizontal displacement can be calculated as: $388 \mathrm{H}_{\mathrm{r}}=\mathrm{H}_{\mathrm{a}}+\mathrm{h}_{\mathrm{v}} / \operatorname{tg}\left(60^{\circ}\right)$. In some case, due to slight curvature, the cutoff point may be difficult to 389 locate. We chose to use a range of possibilities between a minimum position and a maximum 390 position (Fig. 11). Thus, we can deduce a range for the depth of the décollement level which can 391 be compared to the range of the ice/bedrock interface depth inferred by MARSIS.

$393 *$ Location of Fig. 11 (1 column width). 
395 Using the geometric and topographic data, we built various LAPS models. Table 1 and associated 396 Fig. 12 gives the results of the 8 profiles tested. For each profile, we calculated the minimum, 397 maximum and average values of the décollement level vs depth of the bedrock interface. From 398 Fig. 12, it appears that the depths of the décollement levels, deduced from the above models, are 399 in good agreement with the regional depths of the bedrock interface, except for profiles 3a-3a' 400 and $4 b-4 b$ '. For these last profiles, the depth of décollement is overestimated or underestimated 401 by about $1 \mathrm{~km}$ compared to the depth of the bedrock. Of course, these disagreements could be 402 produce by local singularities of the bedrock topography that cannot be detected by Marsis. A 403 byproduct of this test is the horizontal displacement $\mathrm{H}_{\mathrm{r}}$. It appears that the listric fault scenario 404 agrees with a substantial (4-5 $\mathrm{km}$ on the average) horizontal displacement of the ice, 405 corresponding approximately to 0.5 to $1 \%$ of the UL width. These values are consistent with 406 those usually encountered for terrestrial rollover analogs. For instance, the seismic profile 407 presented in Fig. 10 corresponds to a horizontal displacement of about $10 \mathrm{~km}$ (Zhang, 1994).

408

$409 *$ Location of Table 1.

$410 *$ Location of Fig. 12 (1 column width).

\section{Discussion and conclusions}

414 We have provided a complete description of particular polar scarps observed in the ice of UL, a 415 large outlying region of Planum Australe. Cross-analyses of topographic data, optical images, and 416 subsurface radar observations were used to derive a morphologic and stratigraphic scheme for 
417 these scarps that we refer to as LAPS (Large asymmetric polar scarps) because of their particular

418 cross-section with a trough between a straight and a convex upward slope, along with outcrops on

419 the straight slope only. Although the scarps have a weak slope, they commonly reach more than

420 half the thickness of the PLD made up of 1 to $1.5 \mathrm{~km}$ of stacked ice. The LAPSs are numerous

421 and widespread over UL, but they all have similar dimensions.

422 Surface features on Martian PLDs are usually explained in terms of depositional and/or erosion

423 processes. (e.g. Fisher et al., 2002; Howard, 2000; Koutnik et al., 2005; Smith and Holt, 2010).

424 As an alternative process, we suggest a mechanical failure of the ice for the LAPSs origin, based

425 on their striking similarities in shape and size with rollover anticlines above listric normal faults.

426 A quantitative model, based on area balance technique, has been briefly introduced to roughly

427 test this hypothesis by computing some dimensions of a few basic geometries (Davison, 1986;

428 Faure and Seguret, 1988; Gibbs, 1983). It appears that the expected depth of the décollement

429 agrees with the bedrock depth inferred by Marsis for most of the LAPSs. It would be of interest

430 to extend this method in the future to all the LAPSs. This system is also associated with

431 horizontal displacement, computed to be $4-5 \mathrm{~km}$ on average for the LAPSs. This result agrees

432 with what is usually observed for terrestrial rollover analogs, and would imply a substantial

433 global outward sliding of the PLD. Such sliding has already been suggested by Murray et al.

434 (2001) based on fractures observed along with undeformed layers outcropping from Planum

435 Australe margins. Such peripheral fractures could be damping structures resulting from an

436 outward sliding from the heart of UL. The sliding of an ice sheet is a process requiring a weak

437 basal shear stress. Such conditions could be met in case of (i) incompetent basal sediments, (ii)

438 basal sediments softened by melt-water, (iii) over-loaded salt acting as lubricant (Jackson et al.,

439 1994), or (iv) a lower yield stress of Martian ice compared to Earth ice (Banks and Pelletier, 
2008). No information is available to determine whether such sliding could occur at present day

441 or not.

442 Why the PLD exhibits an outward motion is also a major question resulting from the sliding 443 hypothesis. Possible explanations include (i) an active tectonic displacement of the underlying 444 bedrock, (ii) a simple gravitational readjustment of the accumulated ice stack, or (iii) a fluid 445 basal-material naturally dragged up and drained outward by the weight of the glacier.

446 The link between the tectonic hypothesis and the hillocks often observed along the LAPS crests 447 remains to be determined. The hillocks are possibly related to (i) a post-deposition of icy 448 materials, in which case the LAPS topography, under the dominant wind-stream, would generate 449 depressions and cold traps along the crests, (ii) a slight elastic rebound of the footwall after the 450 breaking of the ice, as is commonly observed for Terrestrial tectonic phenomenon (e.g. Weissel and Karner, 1989; Westaway, 1992) and could be in our Martian case a natural consequence of

452 listric faulting, the magnitude of which holds information on the ice rheology, (ii) a rheological 453 response to a change in basal conditions as observed around subglacial lakes on Earth (Remy et 454 al., 1999).

455 A deeper study of possible tectonic activity in UL should be undertaken because of its 456 implications on the ice rheology and PLD basal conditions. In particular, it could be a macro457 expression of fundamental differences between ice-sheet behavior under Martian and Terrestrial 458 conditions, given that the viscosity of ice on Earth would not be expected to generate such 459 faulting. 


\section{Acknowledgements}

470 The Shallow Radar (SHARAD) was provided by the Italian Space Agency and operated by the 471 InfoCom Department, University of Rome 'La Sapienza'. Thales Alenia Space Italia is the 472 prime contractor for SHARAD and is in charge of in-flight instruments and the SHARAD 473 Operations Center. The Mars Reconnaissance Orbiter mission is managed by the Jet Propulsion 474 Laboratory, California Institute of Technology, for the NASA Science Mission Directorate, 475 Washington, DC. Lockheed Martin Space Systems, Denver, Colorado, is the prime contractor of 476 the orbiter. The authors are grateful to the European space agency (ESA) and the French space 477 agency (CNES) for supporting this work. We thank Pierre Beck, Harvey Harder and two 478 anonymous reviewers for their careful reviews that greatly improved this paper.

479

480 


\section{References}

Banks, M. E., Pelletier, J. D., 2008. Forward modeling of ice topography on Mars to infer basal shear stress conditions. Journal of Geophysical Research (Planets). 113, 01001.

Byrne, S., History and current processes of the Martian polar layered deposits. California Institute of Technology, Pasadena, California, 2003.

Clifford, S. M., 1987. Polar basal melting on Mars. Journal of Geophysical Research. 92, 91359152.

Clifford, S. M., et al., 2000. The State and Future of Mars Polar Science and Exploration. Icarus. $144,210-242$.

Cutts, J. A., Lewis, B. H., 1982. Models of climate cycles recorded in Martian polar layered deposits. Icarus. 50, 216-244.

Davison, I., 1986. Listric normal-faults profiles - Calculation using bed-length balance and fault displacement. Journal of Structural Geology. 8, 209-210.

Dula, W. F., 1991. Geometric-models of listri normal faults and rollover folds. Aapg BulletinAmerican Association of Petroleum Geologists. 75, 1609-1625.

Faure, J.-L., Seguret, M., 1988. Importance des modèles de failles dans l'équilibrage des coupes 509 en distension. in L'équilibrage des couches géologiques : buts, méthodes et applications. (Gratier J.P., Ed.), pp-85-92. CAES, Rennes, France. ISSN: 0755-978-X. 85-92. 
511

512

513

514

515

516

517

518

519

520

521

522

523

524

525

526

527

528

529

530

531

532

533

534

Fisher, D. A., et al., 2002. Lineations on the "white" accumulation areas of the residual northern ice cap of Mars: Their relation to the "accublation" and ice flow hypothesis. Icarus. 159, 39-52.

Gibbs, A. D., 1983. Balanced cross-section construction from seismic sections in areas of extensional teconics. Journal of Structural Geology. 5, 153-160.

Gooding, J. L., Possible significance of cubic water-ice, H2O-Ic, in the atmospheric water cycle of Mars. In: L. a. P. Institute, (Ed.), MECA Workshop on Atmospheric H2O Observations of Earth and Mars. Physical Processes, Measurements and Interpretations, 1988, pp. 4649.

Grima, C., et al., 2009. North polar deposits of Mars: Extreme purity of the water ice. Geophysical Research Letters. 36.

Hauge, T. A., Gray, G. G., 1996. A critique of techniques for modeling normal-fault and rollover geometries. In Modern developments in structural interpretations, validation and modeling.

Hays, J. D., et al., 1976. Variations in the Earth's Orbit: Pacemaker of the Ice Ages. Science. 194, $1121-1132$.

Head, J. W., 2001. Mars: Evidence for geologically recent advance of the south polar cap. Journal of Geophysical Research-Planets. 106, 10075-10085.

Head, J. W., et al., 2003. Recent ice ages on Mars. Nature. 426, 797-802.

Head, J. W., Pratt, S., 2001. Extensive Hesperian-aged south polar ice sheet on Mars: Evidence for massive melting and retreat, and lateral flow and pending of meltwater. Journal of Geophysical Research-Planets. 106, 12275-12299.

Herkenhoff, K. E., Plaut, J. J., 2000. Surface Ages and Resurfacing Rates of the Polar Layered Deposits on Mars. Icarus. 144, 243-253. 
535

536

537

538

539

540

541

542

543

544

545

546

547

548

549

550

551

552

553

554

555

556

557

Howard, A. D., 2000. The role of eolian processes in forming surface features of the Martian polar layered deposits. Icarus. 144, 267-288.

Jackson, M. P. A., et al., 1994. STRUCTURAL DYNAMICS OF SALT SYSTEMS. Annual Review of Earth and Planetary Sciences. 22, 93-117.

Jaumann, R., et al., 2007. The high-resolution stereo camera (HRSC) experiment on Mars Express: Instrument aspects and experiment conduct from interplanetary cruise through the nominal mission. Planetary and Space Science. 55, 928-952.

Kargel, J. S., Strom, R. G., 1992. Ancient glaciation on Mars. Geology. 20, 3-7.

Kolb, E. J., Tanaka, K. L., 2001. Geologic history of the polar regions of Mars based on Mars global surveyor data - II. Amazonian period. Icarus. 154, 22-39.

Koutnik, M., et al., 2002. South Polar Layered Deposits of Mars: The cratering record. Journal of Geophysical Research-Planets. 107.

Koutnik, M. R., et al., 2005. Eolian controlled modification of the martian south polar layered deposits. Icarus. 174, 490-501.

Laskar, J., et al., 2002. Orbital forcing of the martian polar layered deposits. Nature. 419, 375377.

Lewis, S. R., et al., 1999. A climate database for Mars. Journal of Geophysical Research-Planets. $104,24177-24194$.

McEwen, A. S., et al., 2007. Mars Reconnaissance Orbiter's High Resolution Imaging Science Experiment (HiRISE). Journal of Geophysical Research-Planets. 112, 40.

McGovern, P. J., et al., 2004. Localized gravity/topography admittance and correlation spectra on Mars: Implications for regional and global evolution (vol 107, pg 5136, 2002). Journal of Geophysical Research-Planets. 109, 5. 
558

559

560

561

562

563

564

565

566

567

568

569

570

571

572

573

574

575

576

577

578

579

580

581

Milkovich, S. M., et al., 2002. Meltback of Hesperian-aged ice-rich deposits near the south pole of Mars: Evidence for drainage channels and lakes. Journal of Geophysical ResearchPlanets. 107.

Murray, B., et al., 2001. Preliminary geological assessment of the northern edge of ultimi lobe, Mars south polar layered deposits. Icarus. 154, 80-97.

Nimmo, F., Stevenson, D. J., 2000. Influence of early plate tectonics on the thermal evolution and magnetic field of Mars. Journal of Geophysical Research-Planets. 105, 11969-11979.

Nouvel, J. F., et al., 2004. Radar signal simulation: Surface modeling with the Facet Method. Radio Science. 39, 17.

Pelletier, J. D., 2004. How do spiral troughs form on Mars? Geology. 32, 365-367.

Picardi, G., et al., 2005. Radar soundings of the subsurface of Mars. Science. 310, 1925-1928.

Plaut, J. J., et al., 2007. Subsurface Radar Sounding of the South Polar Layered Deposits of Mars. Science. 316, 92-96.

Poblet, J., Bulnes, M., 2005. Fault-slip, bed-length and area variations in experimental rollover anticlines over listric normal faults: influence in extension and depth to detachment estimations. Tectonophysics. 396, 97-117.

Pollack, H. N., et al., 1993. Heat flow from the earths interior - Analysis of the global data set. Reviews of Geophysics. 31, 267-280.

Reese, C. C., et al., 1998. Heat transport efficiency for stagnant lid convection with dislocation viscosity: Application to Mars and Venus. Journal of Geophysical Research-Planets. 103, $13643-13657$.

Remy, F. D., et al., 1999. Ice flow physical processes derived from the ERS-1 high-resolution map of the Antarctica and Greenland ice sheets. Geophysical Journal International. 139, 645-656. 
582

583

584

585

586

587

588

589

590

591

592

593

594

595

596

597

598

599

600

601

602

603

604

605

Renno, N. O., et al., 2009. Possible physical and thermodynamical evidence for liquid water at the Phoenix landing site. Journal of Geophysical Research-Planets. 114.

Rognon, P., et al., 2007. The northern ice cap of Mars: an enigmatic evolution compared to the polar environment on Earth. Bulletin De La Societe Geologique De France. 178, 427-436.

Seu, R., et al., 2004. SHARAD: The MRO 2005 shallow radar. Planetary and Space Science. 52, 157-166.

Shelton, J. W., 1984. Listric normal faults - an illustrated summary. Aapg Bulletin-American Association of Petroleum Geologists. 68, 801-815.

Smith, D. E., et al., 2001. Mars Orbiter Laser Altimeter: Experiment summary after the first year of global mapping of Mars. Journal of Geophysical Research-Planets. 106, 23689-23722.

Smith, I. B., Holt, J. W., 2010. Onset and migration of spiral troughs on Mars revealed by orbital radar. Nature. 465, 450-453.

Song, T. G., Cawood, P. A., 2001. Effects of subsidiary faults on the geometric construction of listric normal fault systems. Aapg Bulletin. 85, 221-232.

Tanaka, K., Scott, D., 1987. Geologic map of the polar region of mars. USGS Miscellaneous Investigations Series Map I-1802-C,.

Thomas, P., et al., Polar deposits of Mars. In: H. H. Kiefer, et al., Eds.), Mars. Univ. of Arizona Press, Tucson, 1992, pp. 767-795.

Thomas, P., Weitz, C., 1989. Sand dune materials and polar layered deposits on Mars. Icarus. 81, $185-215$.

Ward, W. R., Long-term orbital and spin dynamics of mars. In: H. H. Kiefer, et al., Eds.), Mars. Univ. of Arizona Press, Tucson, 1992, pp. 298-320.

Weidich, A., Satellite images atlas of glaciers of the world: Greenland. U. S. Geological Survey Professional Paper 1386-C, p.C3, 1995. 
606

607

608

609

610

611

612

613

614

615

616

617

618

619

620

621

622

623

624

625

626

627

628

629

0

25

26

Weissel, J. K., Karner, G. D., 1989. Flexural uplift of the rift flanks due to mechanical unloading of the lithosphere during extension. Journal of Geophysical Research-Solid Earth and Planets. 94, 13919-13950.

Westaway, R., 1992. Analysis of tilting near normal faults using calculus of variations implications for upper crustal stress and rheology. Journal of Structural Geology. 14, 857871.

White, N., et al., 1986. The relationships between the geometry of normal faults and that of the sedimentary layers in their hanging walls. Journal of Structural Geology. 8, 897-909.

Williams, G., Vann, I., 1987. The geometry of listric normal faults and deformation in their hangin walls. Journal of Structural Geology. 9, 789-795.

Zhang, Y. K., 1994. Mechanics of extensional wedges and geometry of normal faults. Journal of Structural Geology. 16, 725-732.

8

19

21

22

23

24


632

633 Table 1. Depth of the décollement level determined for 8 LAPS profiles.

634

\begin{tabular}{|c|c|c|c|c|c|c|c|c|c|c|c|c|c|}
\hline \multirow{2}{*}{ Profile } & \multicolumn{3}{|c|}{ Min. value $(\mathrm{km})$} & \multicolumn{3}{|c|}{ Max. value $(\mathrm{km})$} & \multirow{2}{*}{$\begin{array}{c}\text { Measured } \\
\text { area } \\
\left(\mathrm{km}^{2}\right)\end{array}$} & \multicolumn{3}{|c|}{$\begin{array}{c}\text { Depth of décollement } \\
(\mathrm{km})\end{array}$} & \multicolumn{3}{|c|}{$\begin{array}{c}\text { Depth of bedrock } \\
(\mathrm{km})\end{array}$} \\
\hline & $\mathrm{H}_{\mathrm{a}}$ & $\mathrm{h}_{\mathrm{v}}$ & $\mathrm{H}_{\mathrm{r}}$ & $\mathrm{H}_{\mathrm{a}}$ & $\mathrm{h}_{\mathrm{v}}$ & $\mathrm{H}_{\mathrm{r}}$ & & $\begin{array}{l}\text { Min. } \\
\text { slip }\end{array}$ & $\begin{array}{l}\text { Max. } \\
\text { slip }\end{array}$ & Mean & Min. & Max. & Mean \\
\hline $1 \mathrm{aa}^{\prime}$ & 2.31 & 0.26 & 2.46 & 3.23 & 0.26 & 3.38 & 3.67 & 1.49 & 1.09 & 1.29 & 0.90 & 1.30 & 1.10 \\
\hline $1 b^{\prime}$ & 2.98 & 0.28 & 3.14 & 3.70 & 0.27 & 3.86 & 1.87 & 0.60 & 0.48 & 0.54 & 0.20 & 0.60 & 0.40 \\
\hline $2 \mathrm{aa}^{\prime}$ & 3.00 & 0.43 & 3.25 & 4.10 & 0.45 & 4.36 & 4.37 & 1.35 & 1.00 & 1.17 & 0.70 & 1.11 & 0.91 \\
\hline $2 b^{\prime}$ & 3.20 & 0.35 & 3.40 & 3.80 & 0.34 & 4.00 & 2.75 & 0.81 & 0.69 & 0.75 & 0.70 & 1.11 & 0.91 \\
\hline $3 a^{\prime}$ & 2.10 & 0.19 & 2.21 & 3.70 & 0.22 & 3.83 & 2.29 & 1.04 & 0.60 & 0.82 & 1.08 & 1.50 & 1.29 \\
\hline $3 b^{\prime}$ & 5.70 & 0.40 & 5.93 & 8.80 & 0.40 & 9.03 & 5.82 & 0.98 & 0.64 & 0.81 & 0.36 & 0.76 & 0.56 \\
\hline $4 \mathrm{aa}^{\prime}$ & 4.40 & 0.58 & 4.74 & 5.90 & 0.57 & 6.23 & 5.33 & 1.12 & 0.86 & 0.99 & 0.65 & 1.05 & 0.85 \\
\hline $4 b^{\prime}$ & 3.80 & 0.55 & 4.12 & 6.90 & 0.55 & 7.22 & 8.11 & 1.97 & 1.12 & 1.55 & 0.67 & 1.04 & 0.86 \\
\hline
\end{tabular}

635

636

637

638

639

640

641

642

643

644

645

646 


\section{Figure captions}

651

Fig. 1. Shaded topography of UL (stereographic projection with illumination from the bottomright). The white line is the Planum Australe boundary. The bottom-right insert locates UL within the entire polar plateau. Five black boxes delimit the regions that are enlarged in Fig. 5.

656 Fig. 2. Arch-shaped features are indicated in bold red. The arches marked by X's are LAPSs that 657 exhibit a convex slope with a more complex topography (see section 4.2 for details). White 658 arrows indicate an example of neighboring LAPSs with strictly different orientations.

Fig. 3. (Top) Histogram of the LAPS azimuths. The Y-axis is the number of occurrences. A concavity facing north has an azimuth equal to $0^{\circ}$. A concavity parallel to a longitude and facing decreasing west-longitudes has an azimuth equals $90^{\circ}$. (Bottom) Circular histogram of the relative orientation of the LAPSs in a regional context. The circle border represents 25 occurrences. See section 4.1 for details.

Fig. 4. 3D view of a LAPS (located at the lower right corner of Fig. 5A). Illumination is from the upper-left. Keep in mind that the vertical scale is exaggerated by a factor of 10 . The volume is 45 $\mathrm{km} \times 40 \mathrm{~km} \times 1800 \mathrm{~m}$. The bottom gray area depicts the expected position of the bedrock detected by MARSIS (Plaut et al., 2007), taking into account the $\pm 200 \mathrm{~m}$ uncertainty. Note the 
671 facing a convex slope. The general behavior of the polar layers deduced from the stratigraphic

672 study was added to create a typical model of a LAPS cross-section. The outcrops on the straight

673 slope are outlined, while the downward bending of the subsurface layers is visible below the

674 convex slope. The question mark beneath the LAPS is a reminder that no radar data regarding the

675 subsurface structure are available at the corresponding location (see section 4.2 for details).

676 Hillocks are also present.

677

678 Fig. 5. Five enlargements (A-E) for the corresponding regions indicated in Fig.1. The background 679 map is the unshaded MOLA elevation map. Contour lines are separated by $50 \mathrm{~m}$. Elevation color 680 coding and the spatial scale are the same for all boxes. The black lines locate the cross-sections 681 shown in Fig. 6. The three white rectangles delimit the extent of the images corresponding to the cross-sections in Fig. 7. An example of merging craters that were not taken into account for LAPS counting can be seen at the bottom left of box B (see section 4.1 for details).

Fig. 6. Cross-sections of some LAPSs. The cross-section locations are indicated in Fig. 5. Black 686 lines are the surface and gray areas depict the expected position of the bedrock as retrieved from 687 the interpolated MARSIS map (Plaut et al., 2007), taking into account the 200 m uncertainty. 688 Elevations are indicated in meters, while horizontal lengths are in kilometers. Black arrows show hillocks when present (see section 4.3 for details). Each cross-section is represented by two profiles: (Bottom) Vertical scale multiplied by 10 to highlight the surface shape, (Top) No exaggeration of vertical scale to emphasize the relative flatness and thinness of the system.

693 Fig. 7. Cross-sections (5-5' and 6-6') of two LAPSs, associated with HRSC pictures (DLR/FU 694 Berlin/ESA) and SHARAD radargrams (NASA/ASI). Illumination is from the left. See Fig. 5 for 
695

696

697

698

699

700

701

702

703

704

705

706

707

708

709

710

711

712

713

714

715

716

717 718

locations. The first radargram from the top has its vertical scale multiplied by 10.The last two have a vertical scale multiplied by 30 to emphasize the subsurface echoes. The colored lines in the bottom radargram highlight the behavior of detected subsurface layers. The blue lines are polar layered deposits and the red lines are the putative bedrock deduced by correlation between the SHARAD radargram and the MARSIS basal topography. Black arrows indicate strong echoes that are clutters generated by off-nadir surface reflections.

Fig. 8. Cross-section (7-7') of two successive LAPSs, associated with the HiRISE picture PSP_06222_1055 (NASA/JPL/University of Arizona). Illumination is from the bottom-right. See Fig. 5 for locations. Outcrops of layers occur only on the straight slope of the LAPSs, especially clear on the LAPS on the left . For the LAPS on the right, the cross-section path cuts the end of the LAPS leading to progressive fading of the outcrops.

Fig. 9. Sketches illustrating the typical geometric evolution of hanging-wall deformation in a listric normal fault system. (A) An outward stress breaks the layered material. The dip angle of the resultant fault decreases down to the level of the décollement. (B) Gradual bending of the hanging-wall leads to a rollover anticline geometry. (C) Antithetic faults can follow either directly steps (A) or (B) (modified from Song and Cawood (2001)).

Fig. 10. Seismic profile of a rollover fold associated with a listric fault in the Bohai Gulf of northern China. The vertical scale is in seconds. Note that LAPSs observed on Mars are only made up of pre-tectonic deposits. This rollover fold corresponds to a horizontal displacement of about $10 \mathrm{~km} .1 \mathrm{~s}$ is equivalent to $700 \mathrm{~m}$ on the vertical scale. Modified from Zhang (1994). 
719 Fig. 11. Area balance for extension. Top: Relationship between the undeformed and deformed 720 lengths. The cutoff points are the intersection between the stratigraphic boundaries and the listric 721 fault. For a given stratigraphic horizon, we can identify a footwall cutoff point and a hanging wall 722 cutoff point. The real horizontal extension $\left(\mathrm{H}_{\mathrm{r}}\right)$ is the sum of the apparent horizontal extension $723\left(\mathrm{H}_{\mathrm{a}}\right)$ and the projected cutoff point position $\left(\mathrm{H}_{\mathrm{c}}\right)$. Bottom: Because of the low curvature of the 724 listric fault and the rollover geometry, the position of the cutoff point is uncertain. Two extreme 725 positions are used giving two values of apparent horizontal extension $\left(\mathrm{H}_{\mathrm{a}}\right)$. Uncertainty on the 726 position of the bedrock is represented by a gray band.

727

728 Fig. 12. Graphic illustration of the minimum, maximum and average depth of the décollement 729 level according to the minimum, maximum and average position of the bedrock for the 8 profiles 730 tested. 

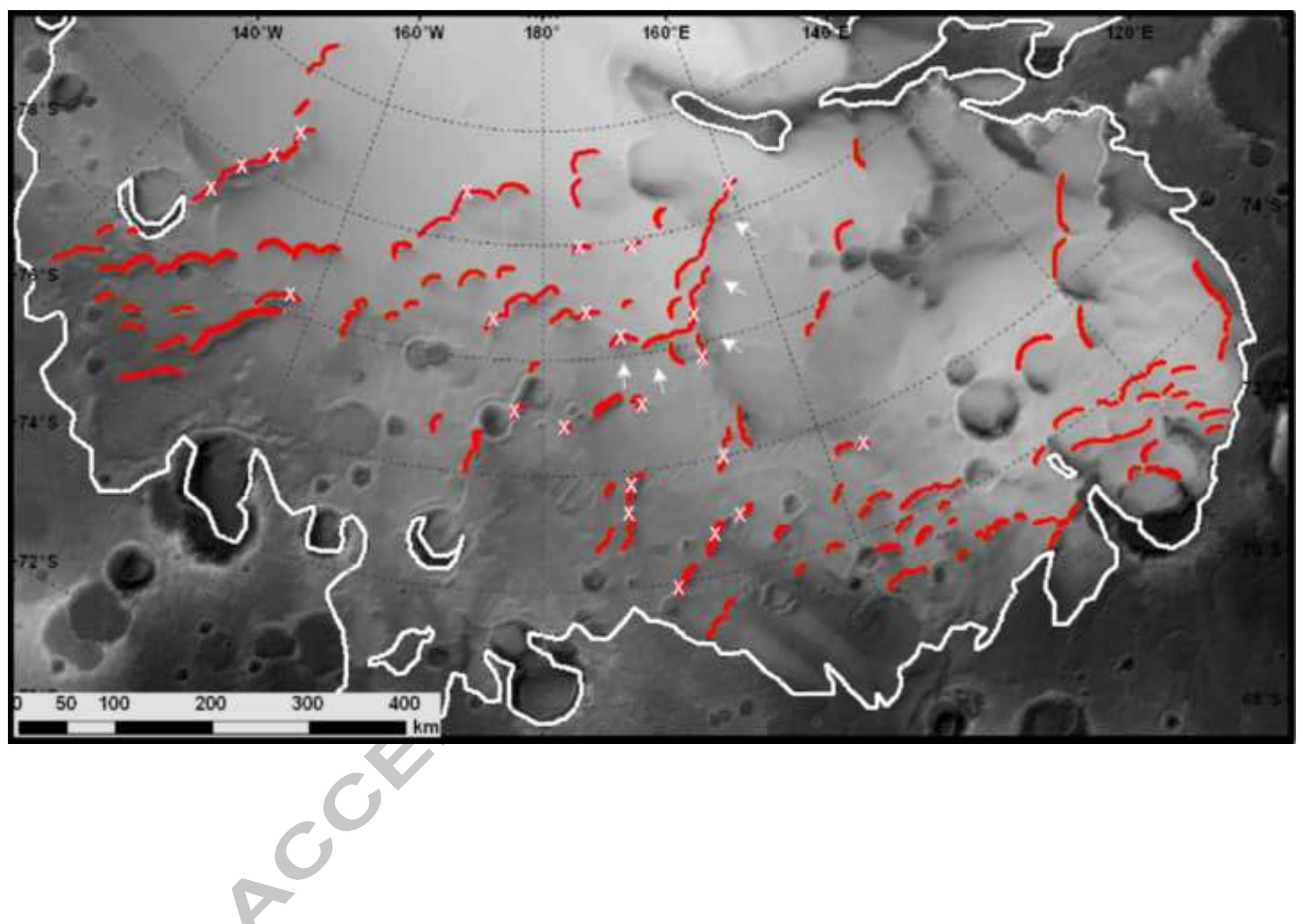


\section{ACCEPTED MANUSCRIPT}

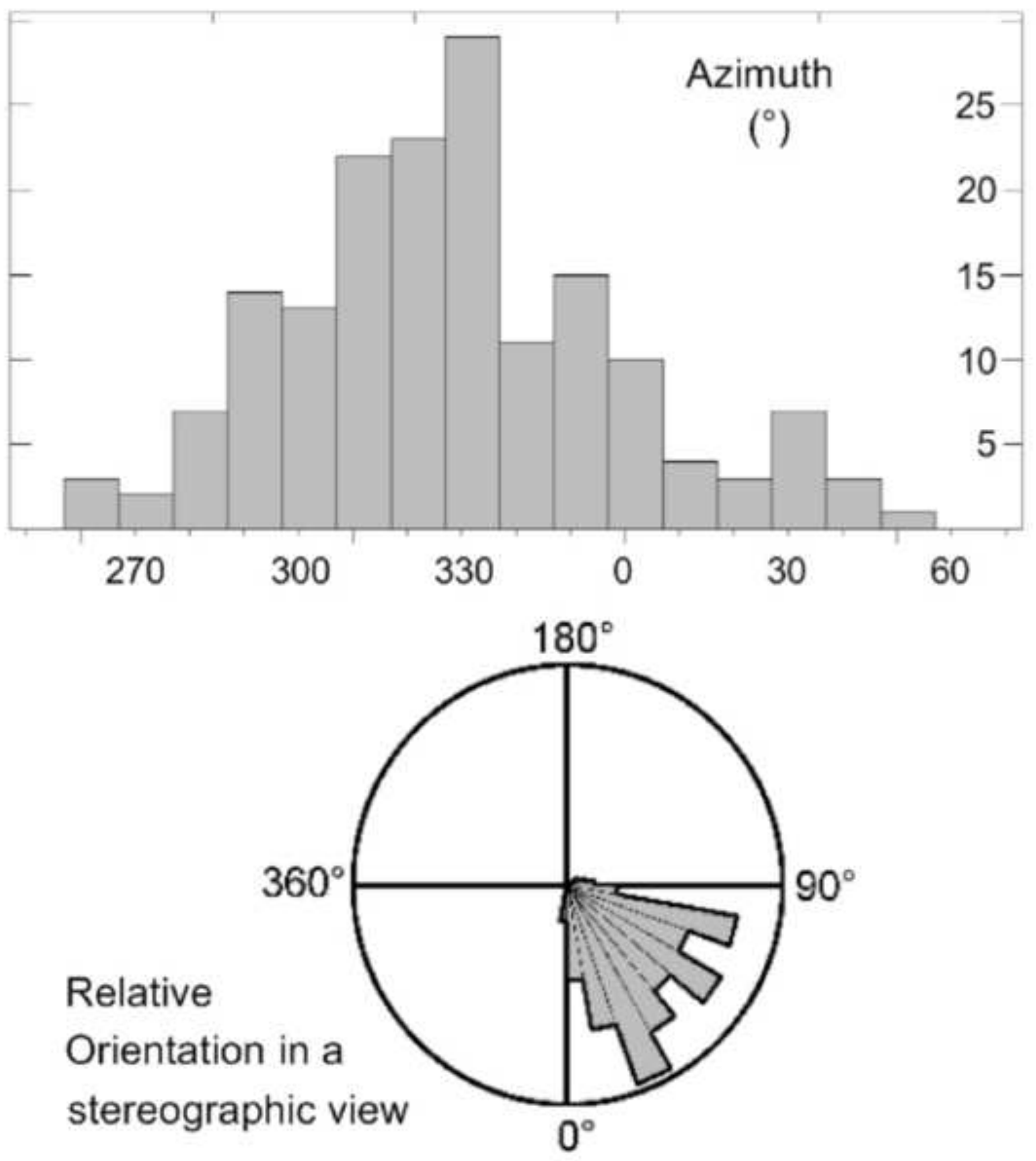

Figure 3

\section{Azimuth}

$\left({ }^{\circ}\right)$

Relative

Orientation in a stereographic view

$$
0^{\circ}
$$



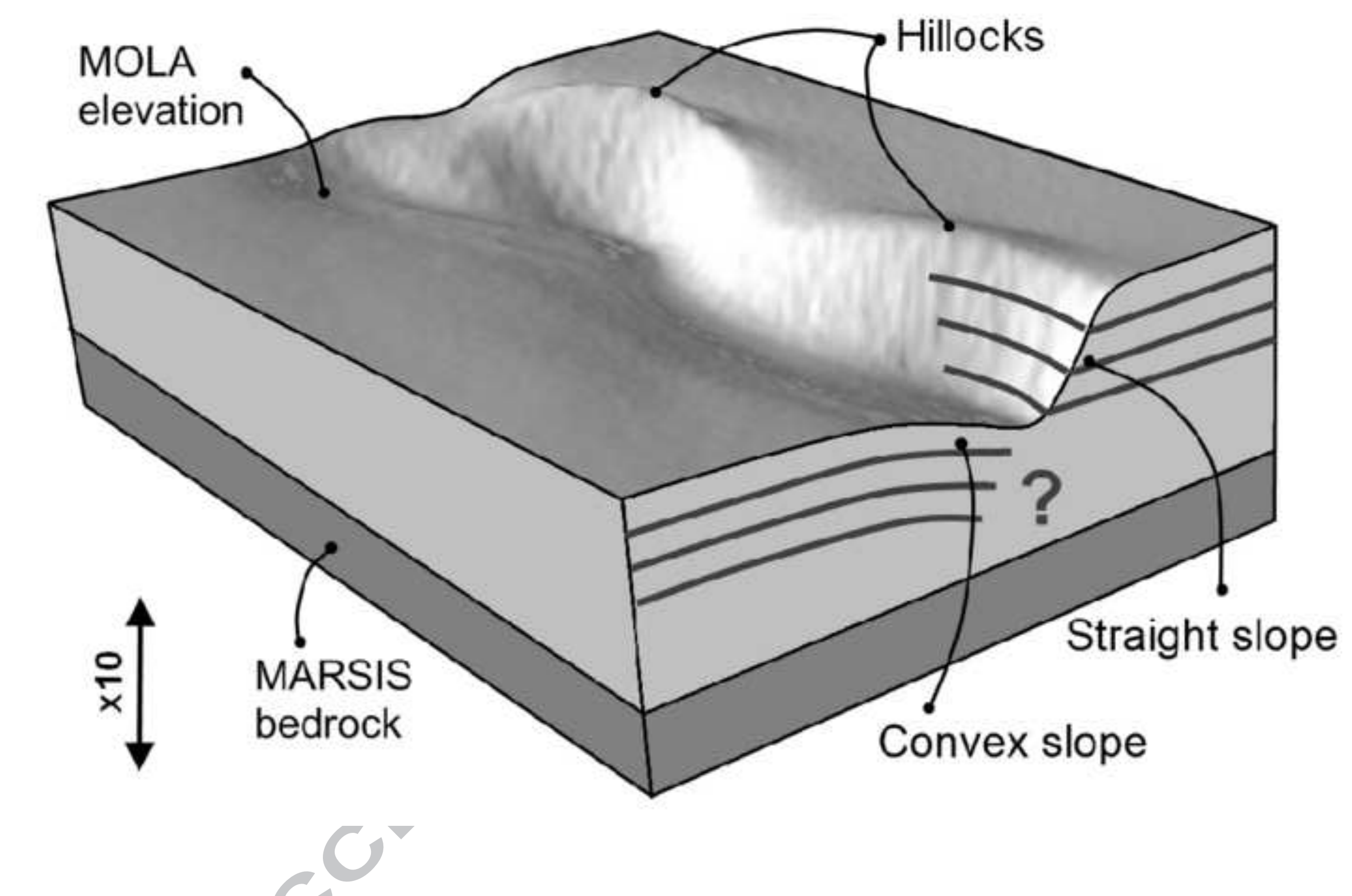


\section{ACCEPTED MANUSCRIPT}
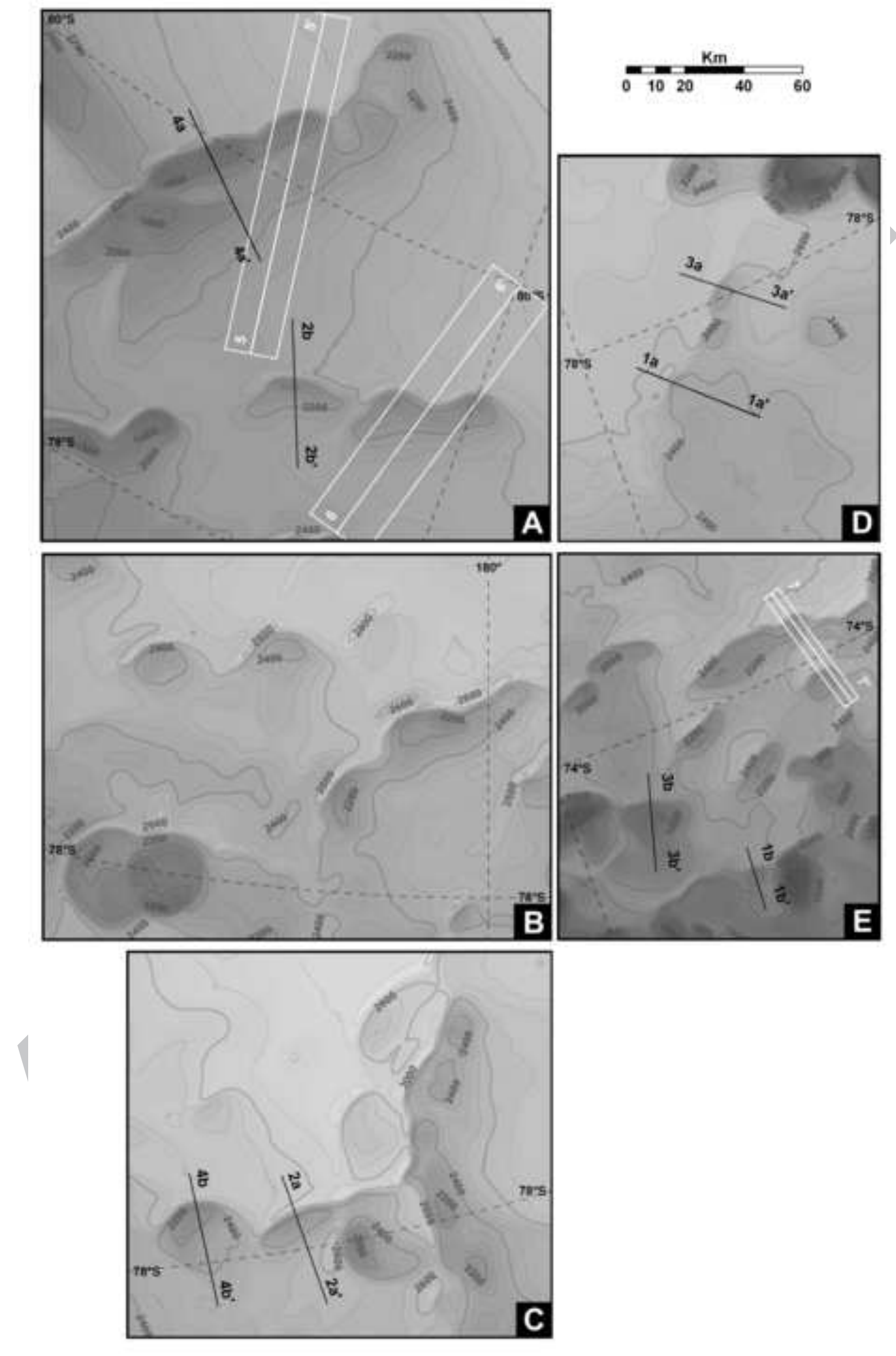

E 
Figure 6

\section{ACCEPTED MANUSCRIPT}

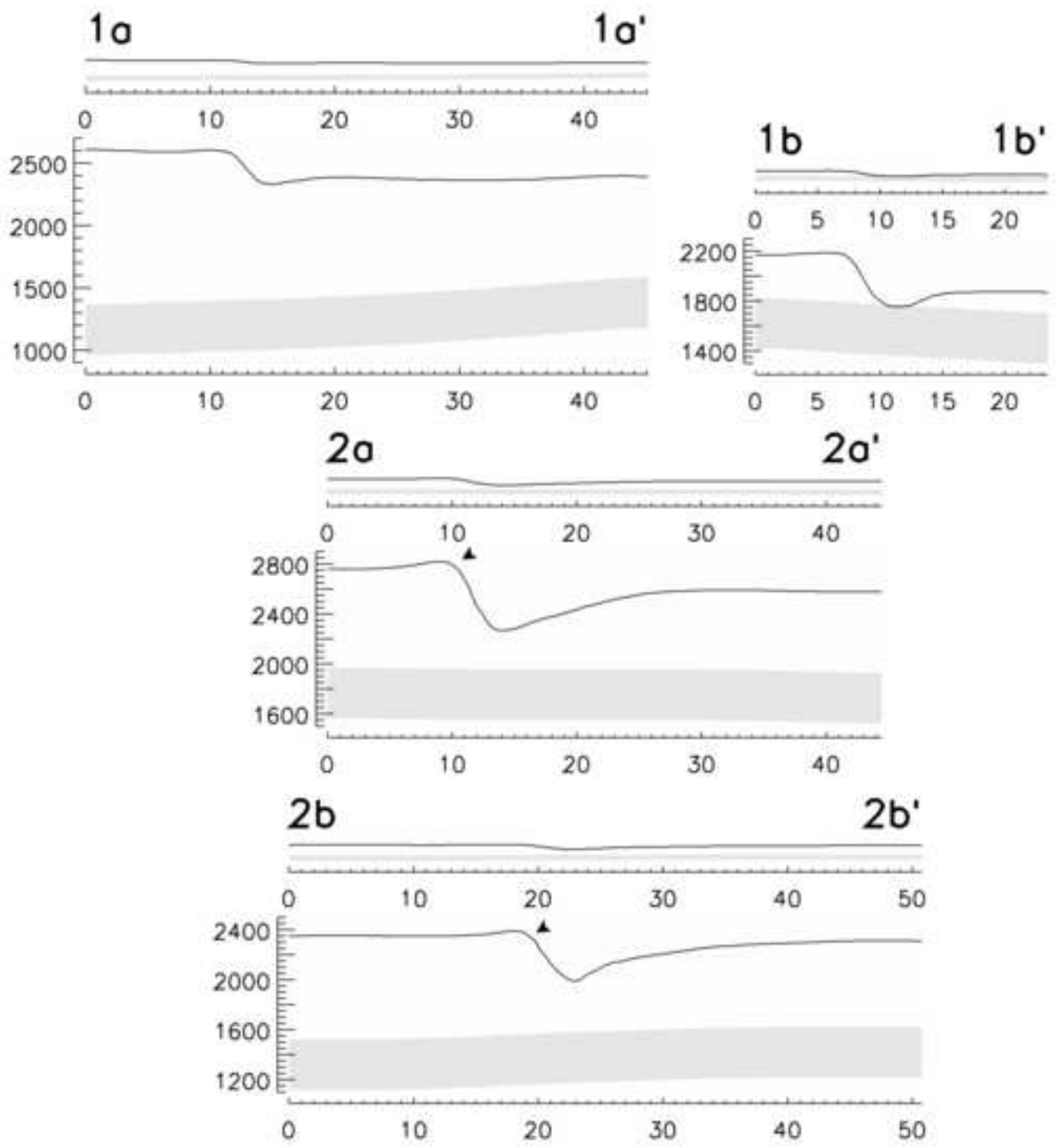




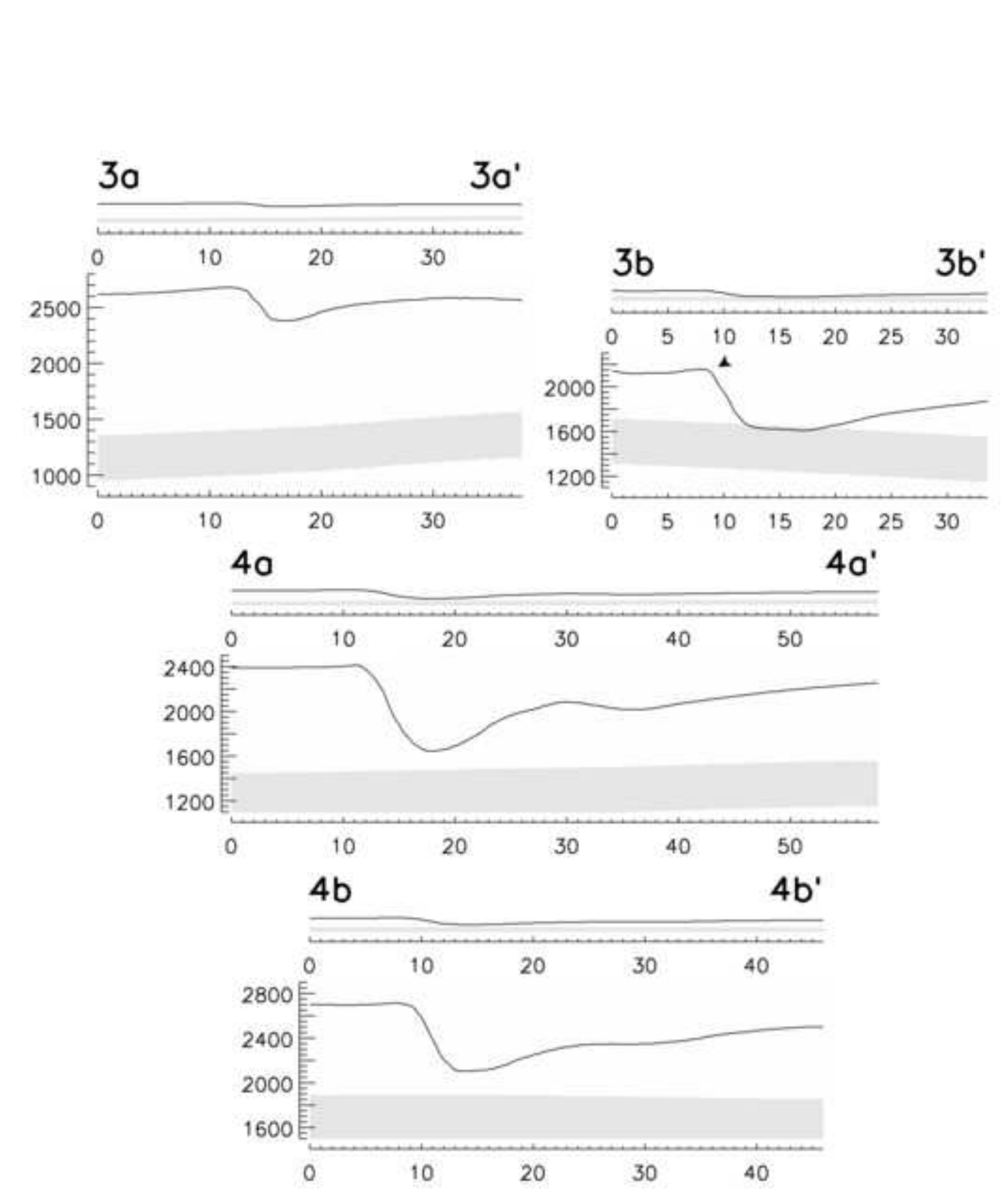

Figure 6 (continued) \\ ACCEPTED MANUSCRIPT}

.

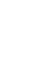
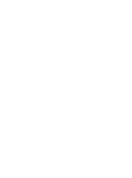

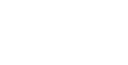


ACCEPTED MANUSCRIPT

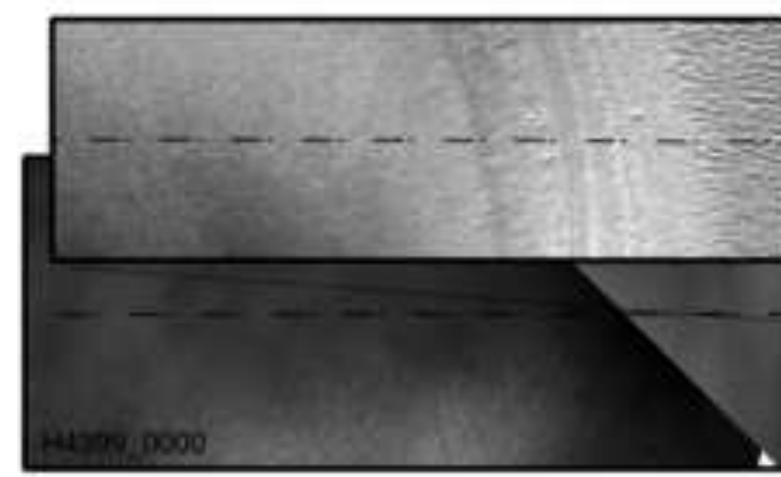

Hasze ooxes

5
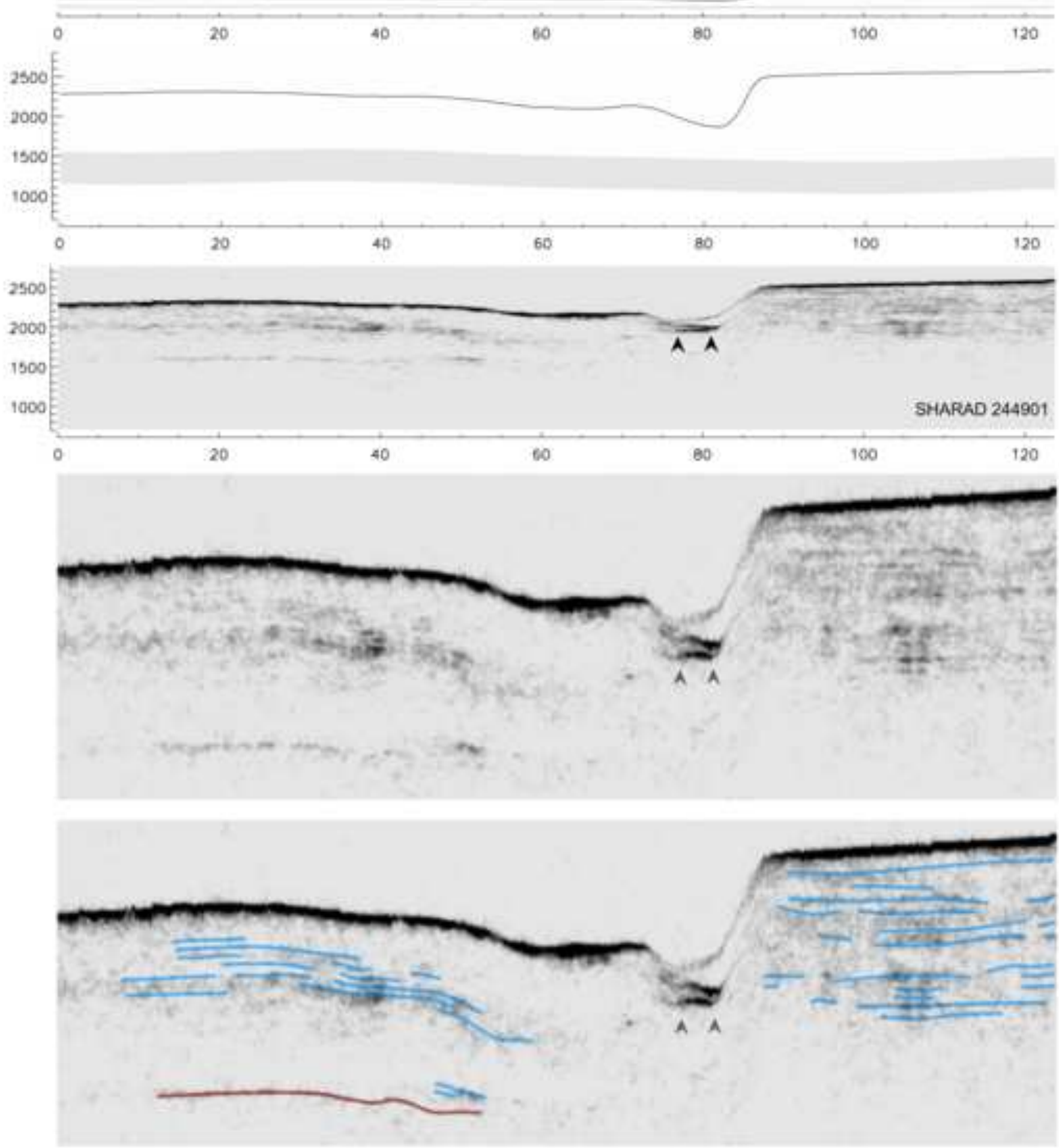


\section{ACCEPTED MANUSCRIPT}
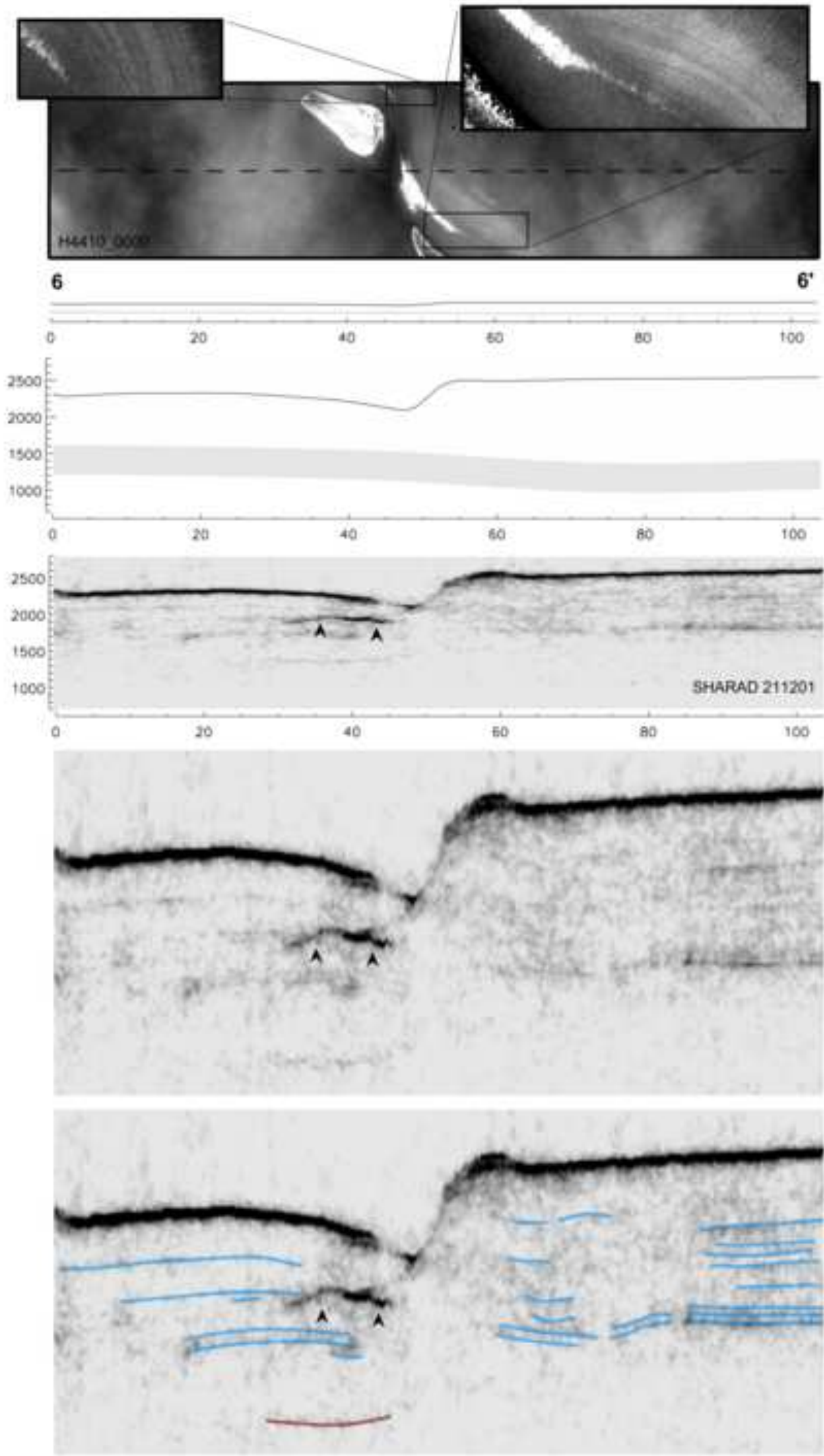


\section{ACCEPTED MANUSCRIPT}
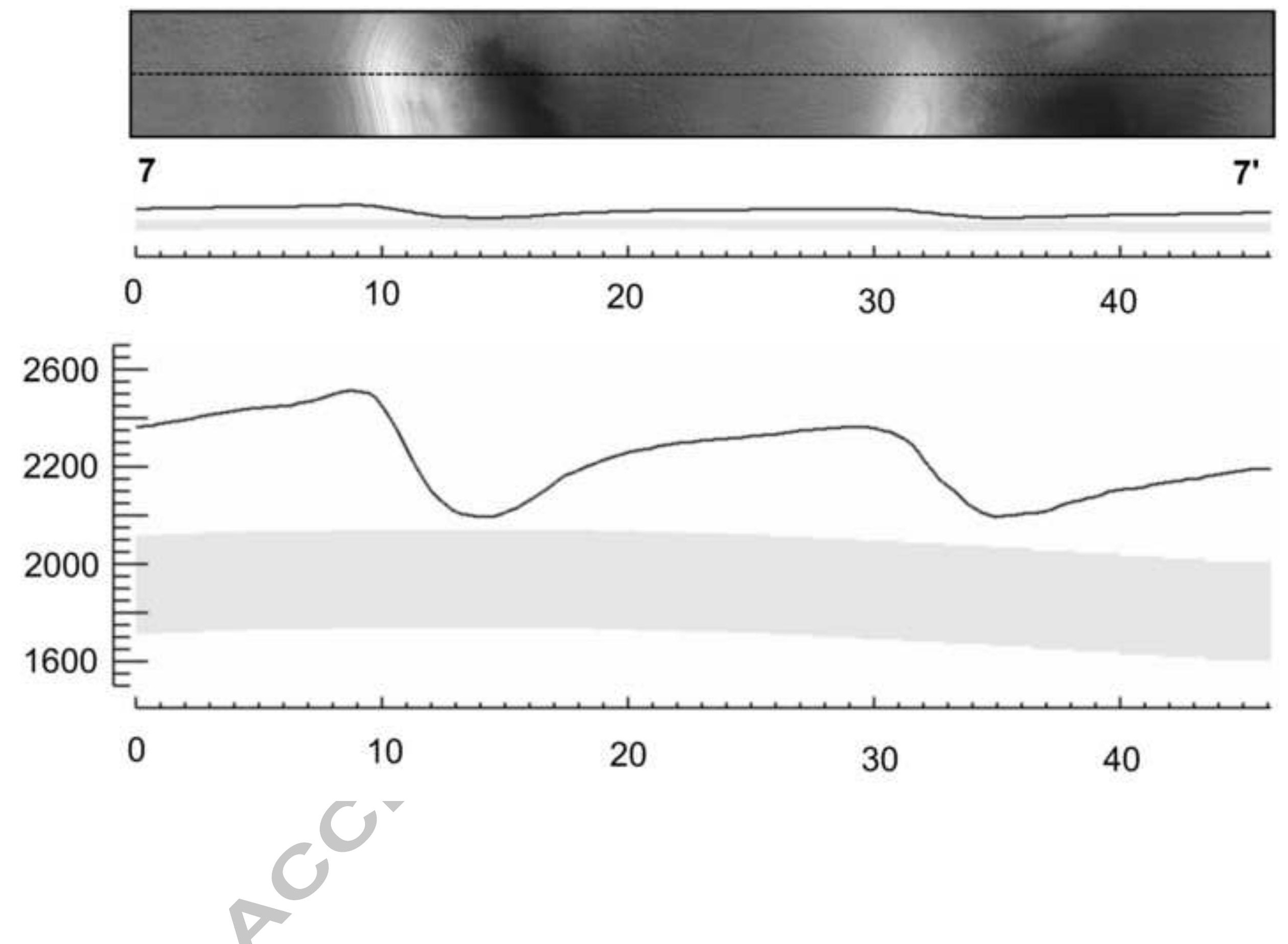
Hangingwall

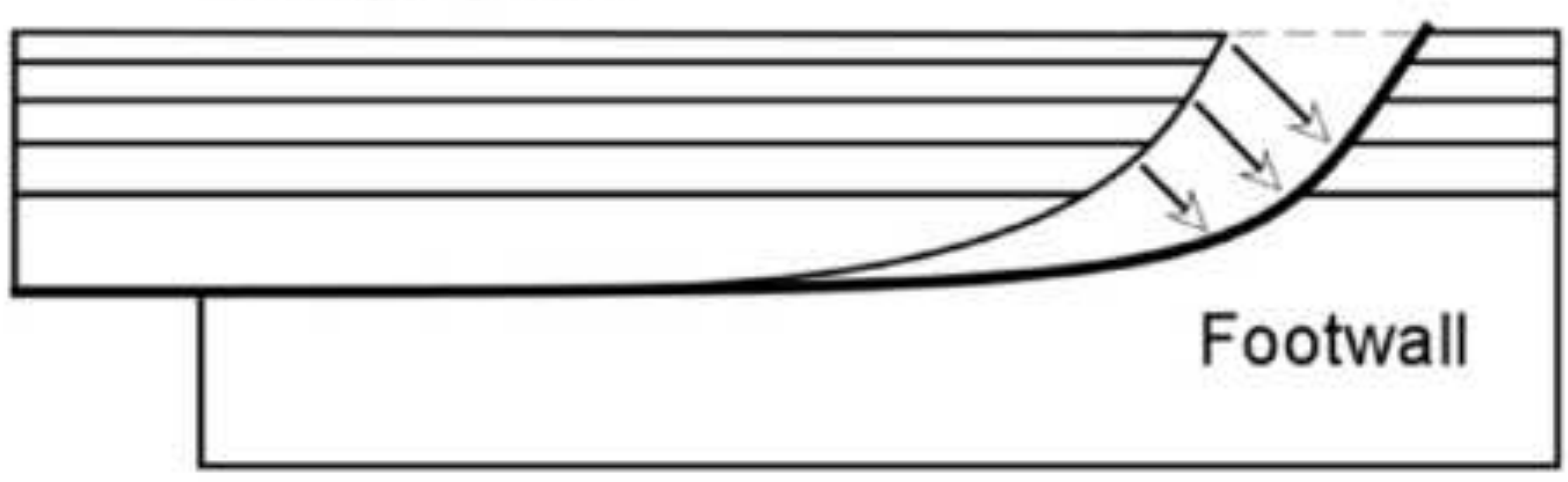

A

Rollover anticline

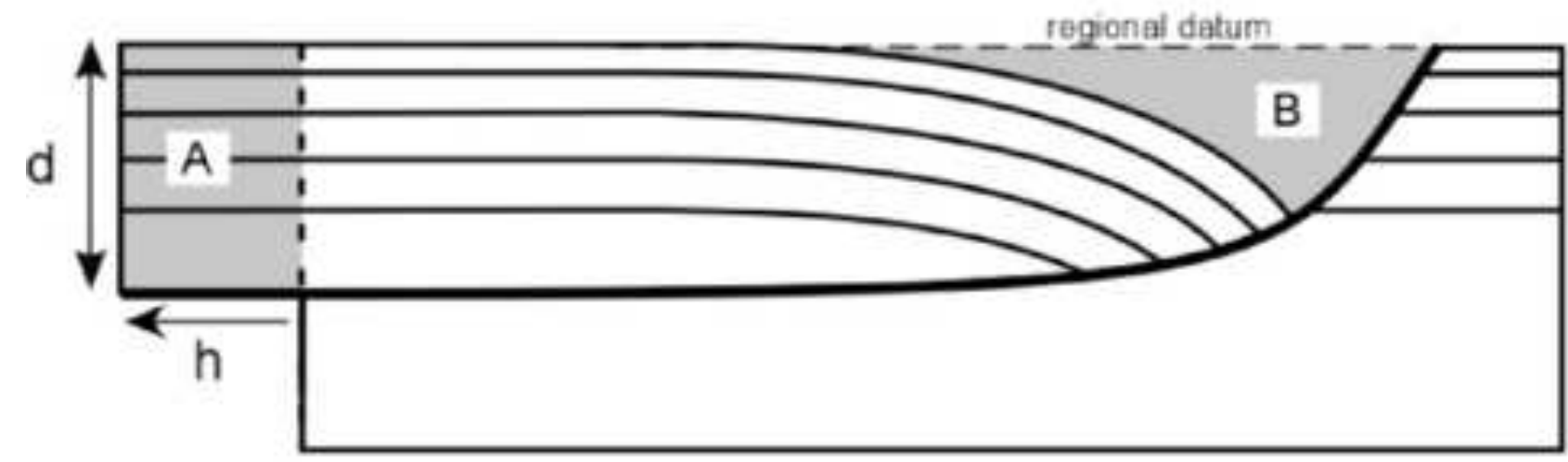

B

Antithetic faults
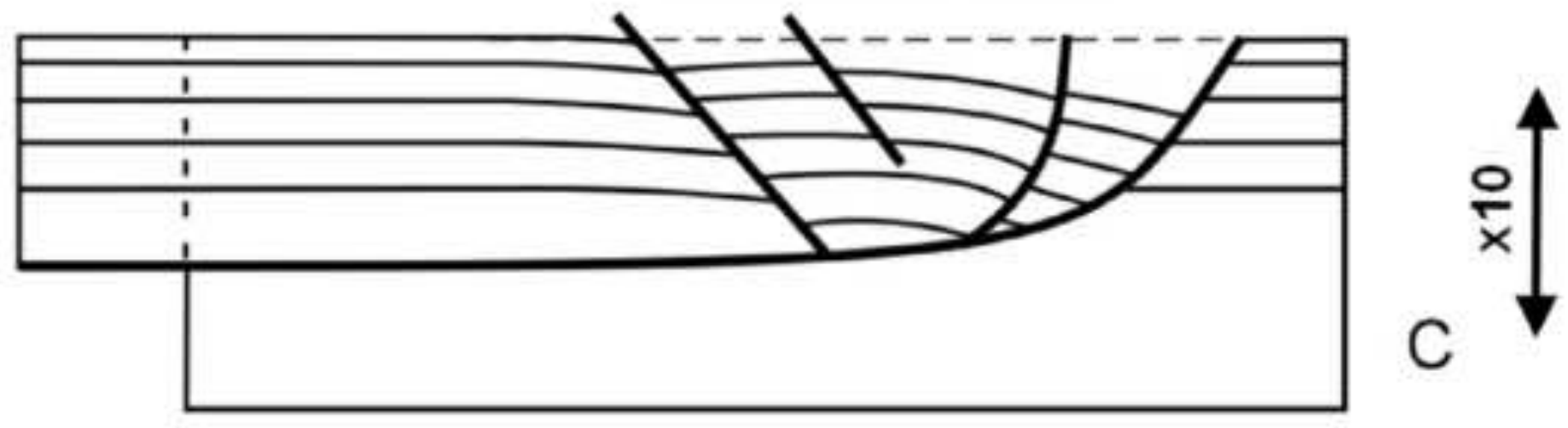


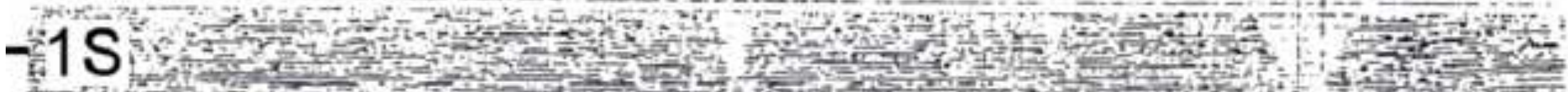
Fin

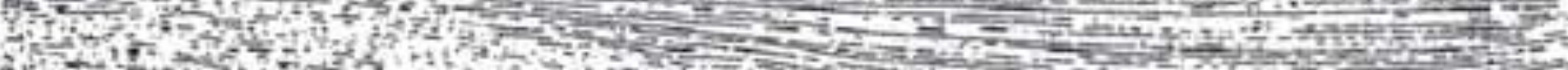

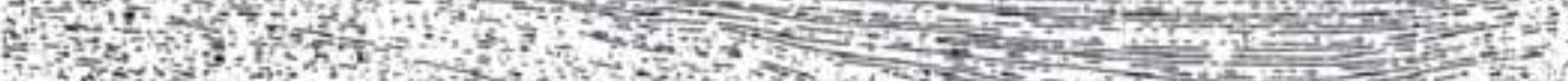

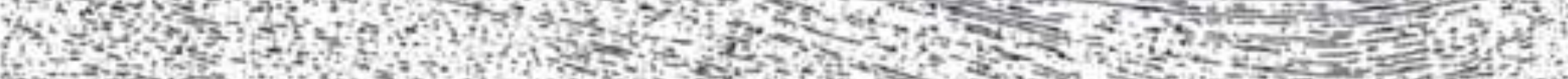

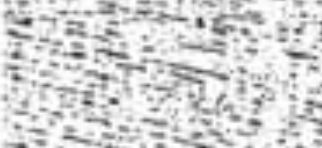

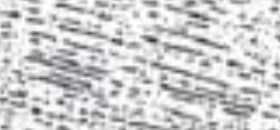

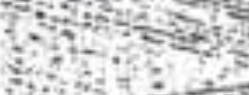

1.6.

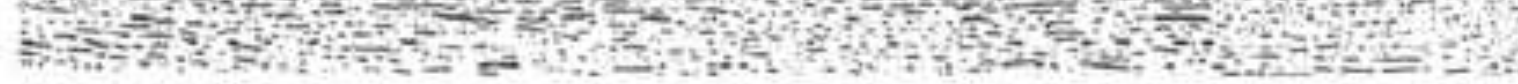

\section{Original profile}

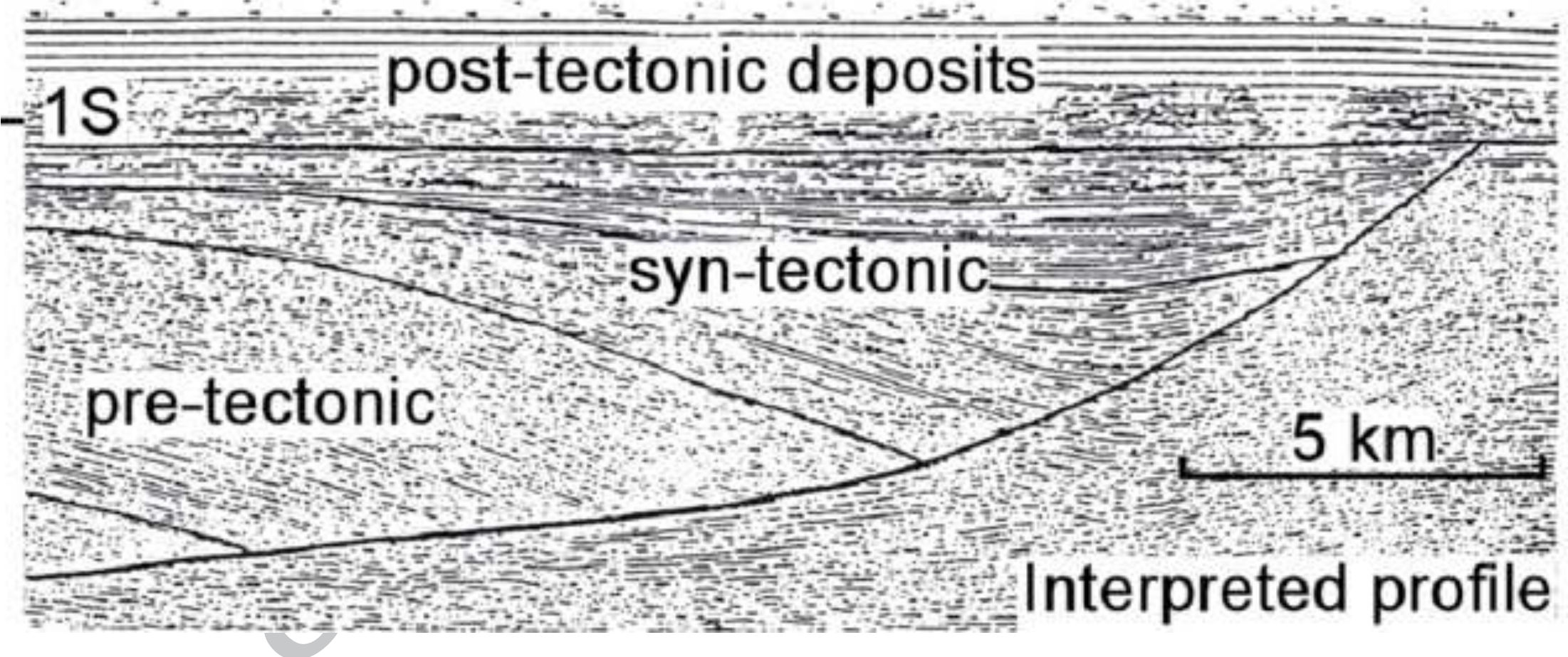



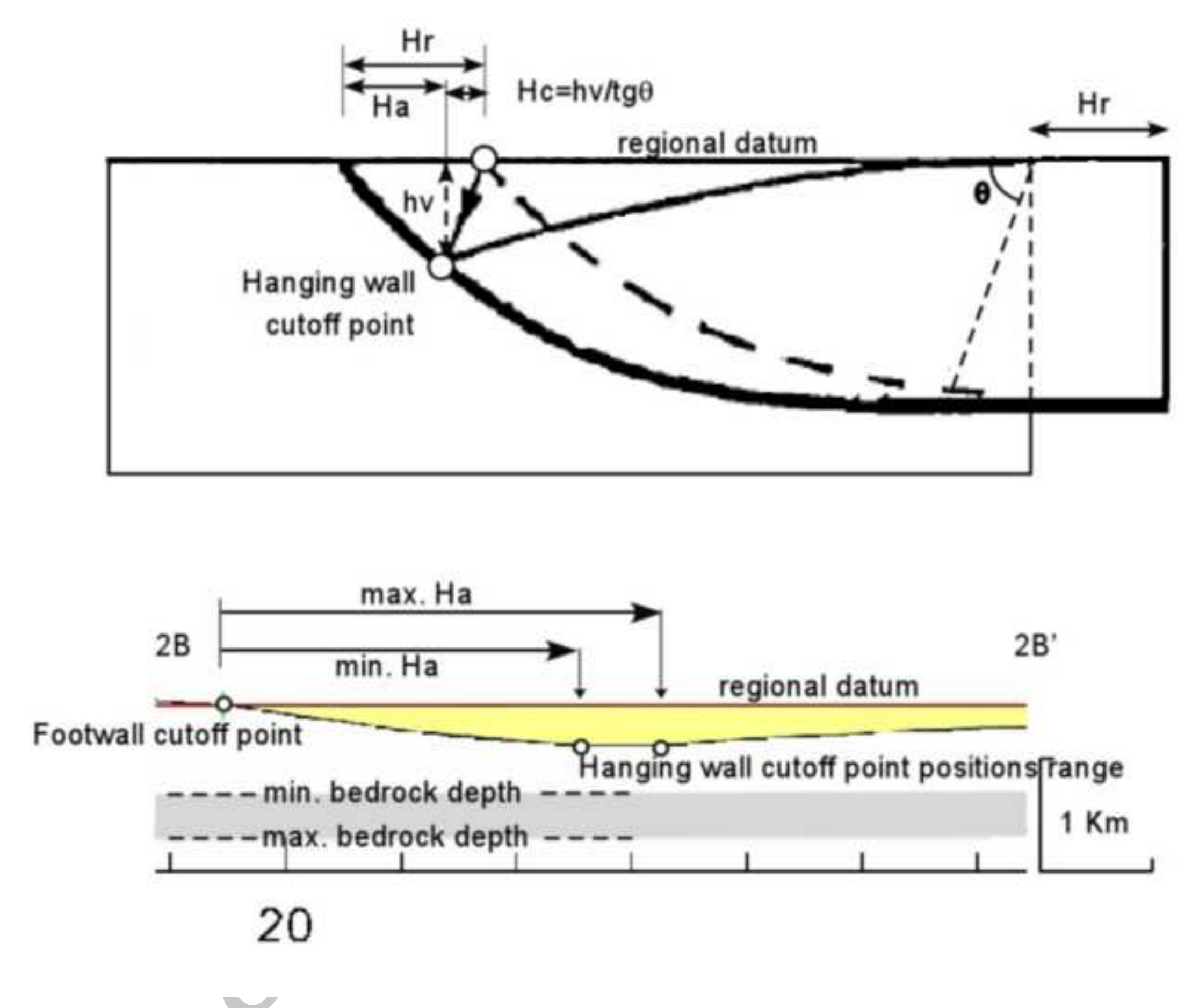

\section{ACCEPTED MANUSCRIPT}

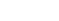

.

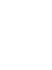
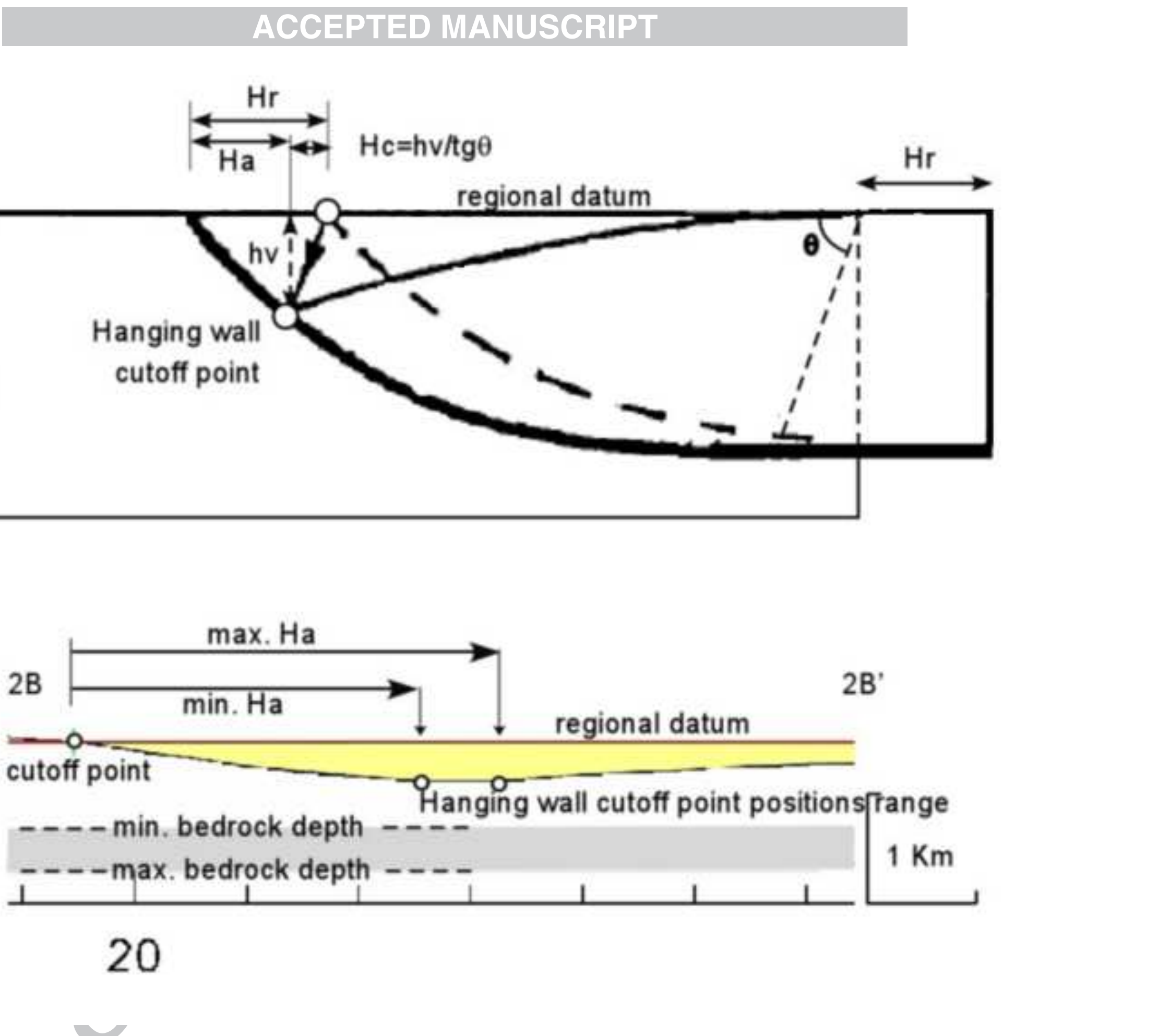

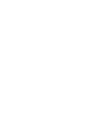




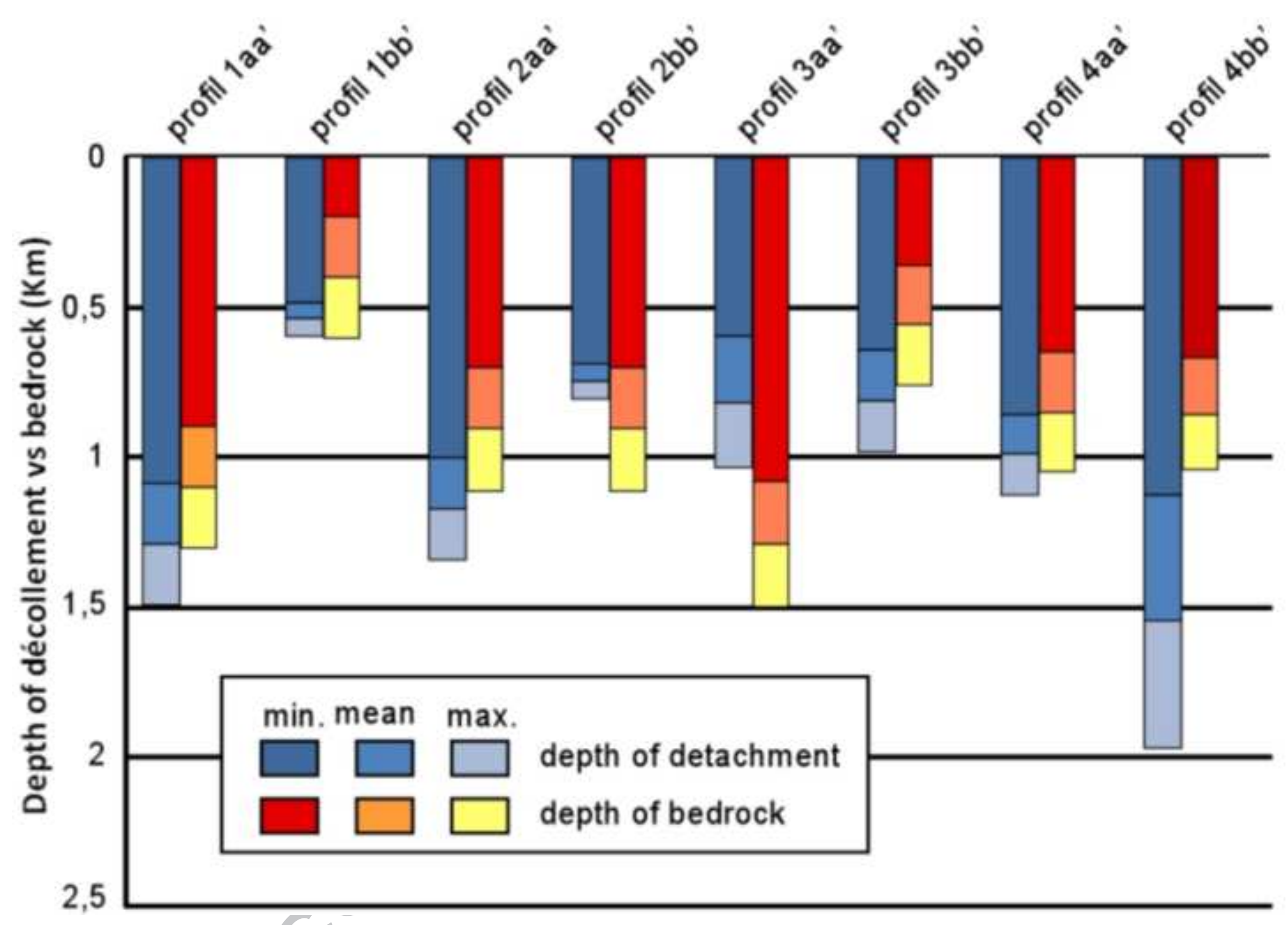

.

.

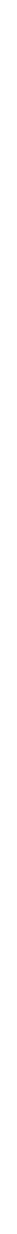




\section{Research Highlights}

733

734

735

736

- The ms makes a new and complete geomorphologic description of intriguing scarps of Planum Australe, using jointly different set of data.

737

738

- This description is similar to the cross-section of a listric normal fault. This allows proposing a new hypothesis regarding the formation process of these scarps, implying a mechanical failure of

740 the ice and a subsequent basal sliding.

741

742

743

- It is emphasized that this process should be study more deeply because of its implications on the ice rheology and basal conditions 